
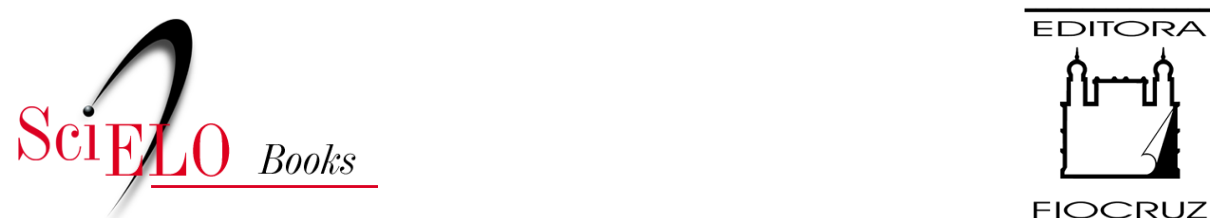

FIOCRUZ

\title{
4. Gastos em saúde
}

\author{
Lígia Giovanella
}

\section{SciELO Books / SciELO Livros / SciELO Libros}

GIOVANELLA, L. Gastos em saúde. In: Solidariedade ou Competição? Políticas e sistema de atenção à saúde na Alemanha [online]. Rio de Janeiro: Editora FIOCRUZ, 2001, pp. 139-184. ISBN: 978-65-5708097-9. http://doi.org/10.7476/9786557080979.0007.

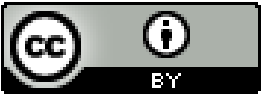

All the contents of this work, except where otherwise noted, is licensed under a Creative Commons Attribution 4.0 International license.

Todo o conteúdo deste trabalho, exceto quando houver ressalva, é publicado sob a licença Creative Commons Atribição 4.0.

Todo el contenido de esta obra, excepto donde se indique lo contrario, está bajo licencia de la licencia Creative Commons Reconocimento 4.0. 


\section{Gastos em Saúde}

A análise dos gastos em saúde é imprescindível para a discussão das reformas setoriais em razão da dominância de aspectos financeiros no debate. Desde a segunda metade dos anos de 1970, quando foi difundida a tese da 'explosão de custos' em saúde, diversas medidas foram implementadas com o objetivo de conter custos e gastos.

Nos últimos anos, ao longo do processo de reforma, os motes que desencadearam cada uma das três etapas da reforma concernem aos gastos nominais crescentes expressos em déficits e, em especial, ao aumento gradual das taxas de contribuição.

$\mathrm{Na}$ discussão a respeito da neccssidade de reformas, outras deficiências do sistema de saúde têm sido trabalhadas a partir, quase sempre, do argumento de que sua resolução contribuiria para o controle da expansão de gastos. A melhoria da qualidade da atenção, a despeito de ter sido aventada, encontra-se subordinada à potencialidade da suposta contenção de gastos.

Sem dúvida, a questão principal dessa discussão tem sido o incremento dos gastos. Daí a necessidade de exame detalhado dos gastos em saúde na Alemanha para apreciar tanto a pertinência e magnitude do problema quanto os resultados das reformas - o impacto das medidas implementadas na evolução dos gastos.

\section{Gastos em Saúde: \\ comparação internacional}

Toda comparação internacional quanto a gastos em saúde é imprecisa não só por problemas de disponibilidade de informações e dificuldades na confrontação de valores monetários, como também em vista das especificidades dos dados 
e dos sistcmas de atençāo à saúde de cada país. Obscrvam-se consideráveis variações das estatísticas oficiais quanto à inclusão de produtos e serviços na qualidade de gastos e/ou consumo em saúde, bem como diversidade dos sistemas de proteção em termos da cobertura e nível de complexidadc e qualidade garantidas, o que dificulta comparação apurada. ${ }^{172}$

A exposição de cada um dos grandes agregados nacionais elude a diversidade das contabilizaçōes nacionais e da abrangência da proteção em saúde nos países, tornando difícil chegar-se a conclusōes precisas quanto à obtençāo de maior ou menor eficiência cm determinado sistema.

As confrontaçōes de dados internacionais, desse modo, servem como aproximação e ilustração de situaçōes problemáticas. Com este intuito, um breve cotejo será aqui realizado.

\section{Gastos totais em saúde per capita com base na paridade do poder de compra}

A OECD tem coletado e divulgado, de modo sistemático, os dados sobre proteção, atenção $\mathrm{c}$ gastos $\mathrm{cm}$ saúde dos países membros. Na busca de aprimoramento, este órgão tem elaborado estimativas que visam a compensar diferenças em tcrmos do custo de vida e viabilizar melhor confrontação. Este é o caso do cálculo dos gastos em saúde per capita com base na paridade do poder de compra, ${ }^{173}$ o qual, além de resolver diferenças de tamanho da populaçāo, reduz vieses monetários.

Em comparação internacional, os gastos totais em saúde na Alemanha podem scr considerados altos. A Alcmanha situa-se cntre os cinco países da OECD com gastos em saúde per capita mais elevados, situação inalterada nos diversos cortes temporais apresentados desde os anos de 1960 (Tabela 13).

Segundo cálculos efetuados pela OECD (1993b; 1997), com base na paridade do poder de compra, em 1990, a Alemanha ocidental ocupava a quinta posição entre os 24 países da OECD com gastos per capita inferiores aos dos EUA, Canadá e Suíça, scndo scguida de perto por França e Suécia. Já em 1995, tais posições haviam se modificado. A Alemanha, entāo unificada, assumiu a quarta posição, antecedida por EUA, Suiça e Luxemburgo e seguida por Canadá e França (Tabela 12).

172 Além disso, grandes agregados nacionais baseiam-se, ao menos parcialmente, em estimativas, retratando apenas de modo aproximado a situação a que se referem.

173 O PPP (Purchasing Power Parity) é uma taxa de conversão de moedas que pretende equalizar o preço de uma mesma cesta de bens e serviços em todos os países, eliminando diferenças nos níveis de preços entre eles e reduzindo efeitos das flutuaçóes das taxas de câmbio (OECD, 1993b). 
Tabela 12 - Gastos totais em saúde per capita com base em PPP* Países da OECD selecionados - 1960-1995.

\begin{tabular}{lrrrrrr}
\hline Países & 1960 & 1970 & 1980 & 1985 & 1990 & 1995 \\
\hline EUA & 143 & 346 & 1.063 & 1.711 & 2.600 & 3.644 \\
Canadá & 109 & 147 & 743 & 1.244 & 1.811 & 2.069 \\
Suíça & 96 & 268 & 939 & 1.224 & 1.640 & 2.412 \\
França & 75 & 203 & 698 & 1.083 & 1.528 & 1.972 \\
Alemanha & 98 & 216 & 811 & 1.175 & 1.522 & 2.134 \\
Suécia & 94 & 271 & 855 & 1.150 & 1.455 & 1.360 \\
Áustria & 69 & 163 & 683 & 984 & 1.383 & 1.634 \\
Itália & 51 & 153 & 571 & 814 & 1.296 & 1.507 \\
Japão & 27 & 127 & 517 & 792 & 1.175 & 1.581 \\
Reino Unido & 79 & 147 & 458 & 685 & 985 & 1.246 \\
\hline
\end{tabular}

* Purchasing power parity, em dólares americanos a preços correntes, para todos os bens c serviços.

Fonte: OECD, 1993b; OECD,1997, para o ano de 1995.

A expansão da proteção à saúde nas décadas de 60 e 70 foi acompanhada de crescimento intenso, dos gastos em saúde nos diversos países da OECD, todavia, observa-se desaceleração na evoluçăo dos gastos em saúde a partir da segunda metade dos anos 80. Esta evolução mais lenta de crescimcnto dos gastos totais pode ser observada na análise dos gastos per capita e na participação dos gastos em saúde no PNB.

Na década de 80, os gastos totais per capita cresceram em ritmo mais rápido na primeira metade do período, e entre 1985 e 1990, a evolução dos gastos sofreu leve desaceleração. A Alemanha destaca-sc neste período. Embora permaneça entre os países com gastos mais elevados, é o segundo país de menor crescimento dos gastos nesses anos entre os países selecionados.

Durante a primeira metade dos anos 90 , o crescimento dos gastos em saúde per capita nos países da OECD selecionados foi ainda mais lento do que o ocorrido entre 1985 c 1990 (tabcla 12). ${ }^{174}$ No que se refere à Alemanha, é delicado analisar esta evolução com base nas comparações internacionais disponíveis, uma vez que os dados, a partir de 1991, refercm-se à Alemanha unificada. Desse modo, o cotejo com anos anteriores năo é adequado. Contudo, vale a pena observar que, na Alemanha, durante a primeira mctade dos anos 90 , os gastos totais per capita cresceram de modo mais acentuado que no período anterior, porém, em ritmo mais lento do que entre 1980 e 1985.

17. Mesmo nos EUA, apesar de apresentarem a terceira taxa mais elevada, os gastos cresceram mais lentamente do que no período anterior. Notadamente, a mais fonte contenção ocorren na Suécia, onde os gastos per capita em saúde sofreram redução de $7 \%$ no período. 


\section{Gastos totais em saúde como proporção do DNB}

A forma mais simples e comum de comparação internacional da magnitude dos gastos em saúde é efetuada por meio da taxa de participação dos gastos em saúde no produto nacional bruto (PNB). Por ser uma proporção e desconsiderar gastos nominais, facilita a confrontação e indica a importância das despesas em saúde para as economias nacionais.

A apresentação de gastos totais em saúde como proporção do PNB sinaliza a importância do setor saúde na economia de cada país por englobar: o consumo de cuidados, produtos e serviços de saúde dos domicílios privados, inclusive os de iniciativa própria dos consumidores; os gastos em saúde de instituiçôes governamentais e não governamentais; investimentos públicos e privados; gastos com pesquisa, desenvolvimento tecnológico (exceto da indústria farmacêutica) e formação na área da saúde.

Com taxas de participação em cxpansāo, que variam entre $6 \%$ e $14 \%$ (1995) do PNB, o setor saúde tornou-se importante ramo da economia nos países da OECD. Os países mais ricos tendem a gastar mais em saúde do que aqueles de renda menos elevada, ${ }^{175}$ contudo, alcançado um certo nível de gastos, nāo há relação progressiva direta entre a renda per capita de um país e gastos em saúdc, seja como gastos pcr capita, seja como participação no PNB (OECD, 1994).

Observam-se expressivas diferenças de gastos em saúde entre países com níveis de renda e cobertura similares que podem ser explicadas pelos distintos desenvolvimentos históricos institucionais, nos diferentes países, com especificidades na organização do sistema de atenção e formas de relacionamento com os prestadores.

Diversos países integrantes da OECD que fomentaram políticas de contenção de gastos nos anos de 1980 tiveram algum êxito na implementação de restriçōes. Durante os anos 80 , como exposto na tabela abaixo, a evolução dos gastos totais $\mathrm{cm}$ saúde como proporção do PNB na maioria dos países da OECD

- foi mais lenta do que na década de 70. Em quatro países - Suécia, Irlanda, Portugal e Dinamarca - ocorreu redução da participação dos gastos totais em saúde no PNB. A Alemanha foi o único país a estabilizar a participação dos gastos totais em saúde no PNB, com variação de 0,1 pontos percentuais, passando de $8,6 \%$, em 1982 , para 8,7\%, em 1992 (tabela 13).

17.5 Os seis países de maior renda per capita - EUA, Suíça, Luxemburgo, Alemanha, Japão e Canadá - sāo aqueles onde se observam gasıos per capia em saúde mais elevados, com exceção do Japão. 
No entanto, não se observa padrão homogêneo de evolução dos gastos em saúde entre os países da OECD. No Canadá, Finlândia, Grécia, Islândia, Itália e Noruega, o acréscimo da participação dos gastos em saúde no PNB foi mais elevado nos anos 80 do que em 70, ao passo que continuou no mesmo ritmo da década anterior nos EUA. ${ }^{176}$ Estes aumentos na Itália e na Grécia ocorreram por políticas deliberadas de expansão de cobertura e ampliação do direito à saúde - reformas sanitárias no sentido do termo que vínhamos utilizando no Brasil.

Tabela 13 - Evolução da participação dos gastos totais em saúde no PNB. Países da OECD - 1972-1992.

\begin{tabular}{|c|c|c|c|c|c|}
\hline Países & 1972 & 1982 & 1992 & $\%$ var. $1982 / 1972$ & $\%$ var. $1992 / 1982$ \\
\hline EUA & 7,6 & 10,3 & 14,0 & 36 & 36 \\
\hline Canadá & 7,2 & 8,4 & 10,1 & 17 & 20 \\
\hline Finlândia & 6,0 & 6,8 & 9,4 & 13 & 38 \\
\hline França & 6,2 & 8,0 & 9,4 & 29 & 17 \\
\hline Suíça* & 5,5 & 7,5 & 9,3 & 36 & - \\
\hline Áustria & 5,4 & 8,0 & 8,8 & 48 & 10 \\
\hline Alcmanha** & 6,5 & 8,6 & 8,7 & 32 & 1 \\
\hline Holanda & 6,7 & 8,4 & 8,6 & 25 & 2 \\
\hline Itália & 5,9 & 6,9 & 8,5 & 17 & 23 \\
\hline Norucga & 5,9 & 6,8 & 8,3 & 15 & 18 \\
\hline Bélgica & 4,3 & 7,4 & 8,2 & 65 & 11 \\
\hline Sućcia & 7,5 & 9,6 & 7,9 & 28 & -18 \\
\hline Reino Unido & 4,7 & 5,9 & 7,1 & 26 & 20 \\
\hline Espanha & 4,4 & 6,0 & 7,0 & 36 & 23 \\
\hline Japão & 4,8 & 6,8 & 6,9 & 42 & 3 \\
\hline Dinamarca & 6,3 & 6,8 & 6,5 & 8 & -3 \\
\hline Portugal & 4,1 & 6,3 & 6,0 & 24 & -5 \\
\hline
\end{tabular}

* O modo de contabilização de gastos cm saúde na Suíça mudou, sendo inadequado o cotejo entre 1982 c 1992 . ** região ocidental.

Fonte: OECD, 1994:37.

A situação da Suécia destaca-se pela importante variação nos gastos desde os anos 80, o que se repete nos anos 90 . Nesse país, que iniciou a década de 1990 com forte recessão e um governo conservador, foi implementada drástica política de ajuste, que controlou a inflação e produziu diversas mudanças e cortes nos

176 Nos EUA ocorreu estabilização da participação dos gastos em saúde no PNB a partir de 1992, permanecendo em torno de $14,1 \%$ (OECD, 1997). 
benefícios sociais. Na saúde, foram contidos os orçamentos hospitalares - oferta predominantemente pública - e, no setor ambulatorial, o pagamento por unidade de serviço foi substituído por um sistema de remuneraçāo por capitação.

Um processo de descentralização foi deslanchado, estabelecendo-se mecanismos de 'competição pública' para hospitais e centros de saúde em alguns condados (Almeida, 1995; Michelsen, 1997). ${ }^{177}$ Quanto ao Reino Unido, chama a atenção o acréscimo da participação dos gastos em saúde no PNB exatamente no período em que foram introduzidos mecanismos de mercado no setor público: o chamado internal market.

O exemplo dos EUA é, por sua vez, suficientemente forte para comprovar que um sistema financiado predominantemente de forma privada tende a produzir gastos mais elevados e que estes são de mais difícil controle. Os EUA são o país com maior renda per capita no mundo c, concomitantemente, com gastos em saúde mais elevados, contudo, cmbora as diferenças de renda com os países mais ricos subseqüentes sejam pequenas, os gastos em saúde per capita chegam a ser o dobro (OECD,1994).

$\mathrm{Na}$ Alemanha, durante os anos 90 , a partir da unificaçāo, a proporção dos gastos em saúde no PNB cresceu, uma vez que foram modificadas as bases de cálculo, a produção econômica na região oriental é menor - a renda per capita é mais baixa - e os gastos em saúde são relativamente altos, próximos àqueles da região ocidental, o que puxa os índices para cima. O aumento da participação dos gastos totais em saúdc no PNB nos anos 90 é também creditado às necessidades de recuperação da rede de atenção da região oriental, bem como de equiparação do seu consumo de serviços e ações ao padrão ocidental.

Segundo dados da OECD (1997), desde 1992 a participaçāo dos gastos totais em saúde na Alemanha como um todo corresponderam a mais de $\mathbf{1 0 \%}$ do PNB. Em 1995, alcançaram 10,4\% ${ }^{178}$ Todavia, quando considerada apenas a regiăo ocidental, a elevaçāo da participação dos gastos em saúde no PNB nos anos 90 foi pequena: inferior a meio ponto percentual (Bundesregienung, 1997a). Assim, em 1995, na região ocidental, os gastos totais em saúde ficaram em 8,6\% do PNB, ocupando a sétima posição no ranking internacional, como mostrado no gráfico a seguir.

177 Em 1994, um novo governo social-democrata assumiu o poder, tendo-se creditado o resultado eleitoral à desaprovação popular da política conservadora de contenção de gastos sociais. 178 Na região oriental, a participação dos gastos tolais em saúde no PNB é bem mais elevada. Em 1994 representavam $13,3 \%$ do produto interno bruto (PIB) correspondente (BMG, 1997). 


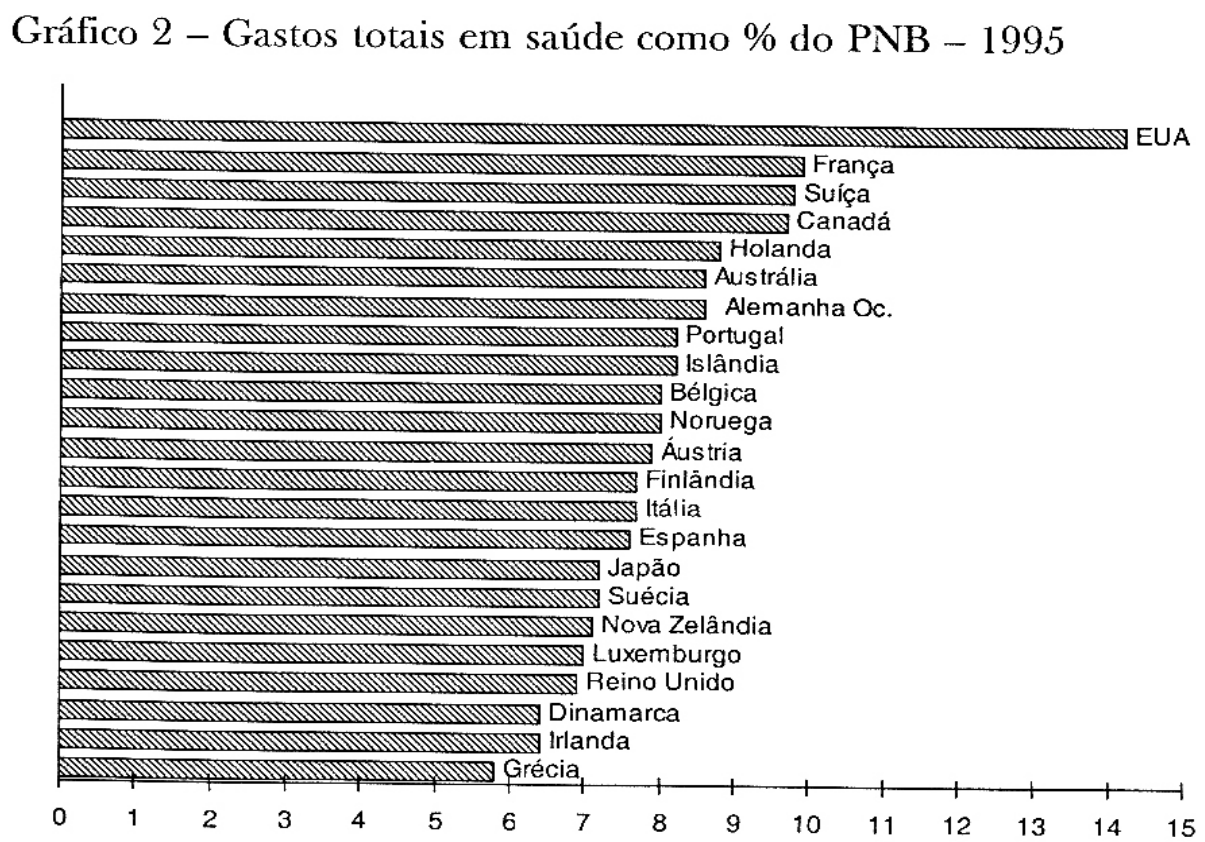

Fonte: OECD, 1997, Hcalth Data for Windows (estimativas preliminarcs); Bundesrcgierung, 1997a.

Cabe lembrar que a participaçāo dos gastos em saúde no conjunto do PNB é influenciada pelas circunstâncias econômicas. Diferentes desempenhos em relação aos gastos com saúde nos diversos países nesse período podem ser parcialmente atribuídos à evolução da economia. Além da questão da reunificação, outra possível explicação para a evoluçāo dos gastos totais em saúde mais acelerada nos anos 90 do que nos 80 na Alemanha é a relação dos mesmos com a evolução da economia.

A Alemanha Ocidental, por conta do processo de reunificação, expcrimentou crescimento cconômico de 5,7\% e 5,0\% do PIB em 1990 e 1991, respectivamente (BMG, 1996). A recessāo foi assim postergada para 1993, quando a evolução do PIB foi negativa: $-1,8 \%$. Esta cvoluçāo da economia justifica em parte a evolução dos gastos totais como proporção do PNB, mais acelerada nos anos 90 do que nos anos 80 .

Importa ainda observar que, embora os gastos totais na Alemanha aumentem sua participação no PNB mais rapidamente nos anos 90 do que nos 80 , não ocorre o mesmo com os gastos do seguro social de doença - GKV, cuja participação no PNB pcrmaneceu estável. 


\section{Papticipação dos gastos públicos nos gastos tolais em saúde}

Conquanto tenha ocorrido desaceleração no ritmo de aumento, os gastos em saúde são e permanecem predominantemente públicos na grande maioria dos países de industrialização avançada. A tabela a seguir mostra a importância do financiamento público para os gastos em saúde nos países da OECD desde os anos de $1970 .{ }^{179}$ Observa-se progressivo aumento da participação dos gastos públicos no conjunto dos gastos em saúde. Gradualmente, maior número de países da OECD teve $70 \%$ ou mais de seus gastos em saúde financiados pelo setor público.

A tendência à elevação da participação dos gastos públicos no conjunto das despesas com saúde manteve-se durante os anos 90. Em 1996, os gastos públicos representavam $70 \%$ ou mais das despesas com saúde em 20 países - dentre os 25 da OECD. Em 50\% destes, os gastos públicos correspondiam a mais de $80 \%$.

Tabela 14 -Participação (em \%) dos gastos públicos nos gastos totais em saúde. Países da OECD selecionados - 1970-1996

\begin{tabular}{lcccc}
\hline & 1970 & 1980 & 1990 & 1996 \\
\hline Alemanha & 73.3 & 79.2 & 76.8 & 78.3 \\
Áustria & 63.0 & 68.8 & 75.0 & 74.9 \\
Bélgica & 87.0 & 83.4 & 88.9 & 87.7 \\
Canadá & 70.2 & 75.7 & 74.6 & 71.4 \\
Dinamarca & 86.3 & 85.2 & 82.3 & 79.4 \\
Espanha & 65.4 & 79.9 & 78.7 & 76.3 \\
EUA & 37.8 & 42.4 & 40.8 & 47.0 \\
França & 74.7 & 78.8 & 74.5 & 80.7 \\
Holanda & 84.3 & 74.7 & 72.7 & 77.0 \\
Itália & 86.9 & 80.5 & 78.1 & 69.9 \\
Japão & 69.8 & 71.3 & 77.6 & $* 78.4$ \\
Noruega & 91.6 & 85.1 & 83.3 & 82.5 \\
Portugal & 59.0 & 64.3 & 65.5 & 59.8 \\
Reino Unido & 87.0 & 89.4 & 84.1 & 84.3 \\
Suécia & 86.0 & 92.5 & 89.9 & 80.2 \\
Suíça & 63.9 & 67.5 & 68.4 & 71,9 \\
\hline
\end{tabular}

* Dado referentc a 1995.

Fonte: OECD Health Data 97 - Health Data for Windows.

179 Em 1960, na maioria desses países, os gastos públicos correspondiam a mais de $50 \%$ dos gastos em saúde, mas apenas em oito deles alcançavam $70 \%$. 
Mantém-se, portanto, a predominância dos gastos públicos no conjunto dos gastos em saúde durante os anos 90 . Contudo, observa-se, a partir dos anos 80 , redução da participação dos gastos públicos no conjunto dos gastos em saúde em cerca da metade dos países da OECD, dados estes tidos como comprovatórios do êxito das políticas de contenção. Na maioria dos países em que ocorreu, a redução foi leve, com queda menor do que cinco pontos percentuais para o período de 15 anos. ${ }^{180}$ Mesmo com tais diminuiçōes, a proporção dos gastos em saúde pública foi mais elevada em 1996 do que em 1970.

$\mathrm{Na}$ Alemanha, ainda que a participação dos gastos públicos no conjunto dos gastos não seja das mais altas, nunca tendo atingido $80 \%$, permanece acima de $70 \%$ desde 1970, mostrando oscilações pouco acentuadas. Durante os anos 80, ocorre leve redução. Na década de 90 , segundo os dados apresentados, houve pequeno acréscimo da participação dos gastos públicos no total de gastos em saúde, em especial por conta da inclusāo no cômputo, dos gastos relativos à Região Oriental.

A preponderância do financiamento público da atenção à saúde entre os países da OECD - os países de maior renda per capita - mostra a nāo vigência na prática da proposição conservadora, que apela à subsidiariedade e prega a desresponsabilização do Estado: 'quem pode, deve pagar'. Ainda que o apelo à responsabilidade individual seja manifesto, os dados mais recentes continuam a mostrar que o financiamento público é a forma dominante de garantia de acesso aos cuidados de saúde nos países da OECD no total das despesas com saúde. Essa observação é da maior importância para a discussāo da situaçāo no Brasil. Sinaliza ser o financiamento público imprescindível para a garantia de cobertura de proteção à saúde mesmo para populaçōes cujo nível de renda é muito mais elevado do que o dos brasileiros.

\section{Gastos Totais em Saúde na Nemanha}

Na Alemanha, em 1994, último ano com dados gerais divulgados oficialmente, os gastos totais em saúde, inclusive transferências financeiras, foram de 470 bilhões de marcos - cerca de 280 bilhões de dólares. ${ }^{181}$ Destes, 84,5\% (397 bilhões de marcos) são relativos à região ocidental, e 15,5\%, à regiāo oriental. As açōes curativas constituem o principal item de despesas: $58,5 \%$ do total dos gastos

180 Houve elevação da participação dos gastos públicos em menor número de países, em especial naqueles de participação inicial menos elevada, como Japão, Suíça e EUA.

181 Na contabilização de gastos totais em saúde realizada pelo SıBA são computadas todas as despesas referentes à assistência médico-sanitária, às despesas com pesquisa e formaçăo na área da saúde e ao consumo de bens e produtos relativos à saúde assim como despesas com benefícios em espécie - transferências financeiras aos indivíduos em conseqüêtucia de adoecimento. 
em saúde (274,5 bilhões de marcos) foram despendidos em tratamento médicoodontológico (ambulatorial, hospitalar, medicamentos e próteses) (StBA, 1997).

Aos gastos com ações médico-sanitárias seguem-se aqueles com transferências financeiras (auxílio-doença e aposentadorias precoces por invalidez) e medidas de reabilitação (benefícios que sucedem ao episódio de doença), em um volume de 129,1 bilhões de marcos que correspondem a $27,5 \%$ do total.

Apenas pequena parcela dos gastos totais em saíde, cerca de $7,4 \%$, equivaleu a despesas com medidas preventivas e de acompanhamento. Com formação profissional e pesquisa universitária na área foram gastos 8,2 bilhōes $(1,7 \%)$.

\section{Gastos totais em saúde segundo fonte de financiamento}

Os gastos cm saúde na Alemanha, como apresentado na seção anterior, são predominantemente públicos. A maioria dos gastos públicos (81\%) é proveniente de receitas de contribuiçāo dos diversos seguros sociais. O Seguro Social de Doença (GKV) arca com cerca da metade $(47,9 \%)$ do conjunto de todos os gastos em saúde. A Previdência Social e o Seguro Social de Acidentes são responsáveis, respectivamente, por $7,7 \%$ e $3,3 \%$ dos gastos totais. ${ }^{182}$

Tabela 15 -Distribuição dos gastos totais em saúde, inclusive transferências financeiras, segundo ordenadores de despesas.* Alemanha - 1970-1994.

\begin{tabular}{lrrrrrrr|r}
\hline & \multicolumn{7}{c|}{ Região Ocidental } & BRD \\
\hline Fonte & 1970 & 1980 & 1990 & 1991 & 1992 & 1993 & 1994 & 1994 \\
\hline Orçamento Público & 14,2 & 13,5 & 13,3 & 13,4 & 13,3 & 13,9 & 13,2 & 13,4 \\
GKV & 35,5 & 45,9 & 46,0 & 47,9 & 47,4 & 45,4 & 46,5 & 47,9 \\
Previdência Social & 9,4 & 6,1 & 6,6 & 6,7 & 6,2 & 7,1 & 7,2 & 7,7 \\
Scg. Soc. Acidentes & 3,6 & 3,3 & 3,0 & 2,9 & 3,4 & 3,7 & 3,7 & 3,3 \\
\hline Subtotal Público & 62,6 & 68,8 & 68,9 & 70,9 & 69,9 & 70,0 & 70,6 & 72,3 \\
\hline Scg. Priv. Saúdc & 5,2 & 4,6 & 5,7 & 5,1 & 5,7 & 5,8 & 5,9 & 5,3 \\
Empregadores & 23,7 & 19,6 & 17,6 & 16,3 & 16,7 & 16,4 & 15,5 & 14,7 \\
Domicílios Privados & 8,5 & 7,0 & 7,8 & 7,6 & 7,7 & 7,8 & 8,0 & 7,7 \\
\hline Subtotal Privado & 37,4 & 31,2 & 31,1 & 29,0 & 30,1 & 30,0 & 29,4 & 27,7 \\
\hline
\end{tabular}

* As contribuiçõcs de cmpresários e trabalhadores cstão contabilizadas apenas nos respectivos scguros sociais. No orçamento público não estāo computados os gastos $\mathrm{em}$ saúde dos cmpregadorcs públicos (auxílio-doença, contribuições).

Fonte: StBA, 1996 e 1997.

182 Referentes ao pagamento de aposentadorias por invalidez, as medidas de reabilitação $\mathrm{cm}$ casas de repouso $(K u)$, pagamentos de aposentadorias, tratamento de acidentados e prevenção de acidentes. 
Os gastos públicos provenientes das receitas de impostos (gastos fiscais) correspondem a apenas $13,4 \%$ do conjunto dos gastos totais. União, estados e municípios gastaram 63 bilhões de marcos com medidas ligadas à saúde em 1994. Destes, 17,2 bilhões corresponderam a medidas para reabilitaçāo social e profissional, 16,8 bilhões foram pagos a cuidados de enfermagem de longa duração (Pflege) pela assistência social e 11,3 bilhões de marcos destinaram-se ao financiamento de hospitais públicos e hospitais universitários. Os orçamentos públicos são ainda responsáveis por gastos com formação do pessoal da área de saúde ( 8,2 bilhōes) e com os centros de saúde públicos (Gesundheitsdienst) responsáveis por programas preventivos, com os quais foram gastos, em 1994, 3,9 bilhões de marcos alemães.

A participação dos gastos públicos varia conforme o tipo de despesa. Entre os gastos com tratamento em saúde, todos os tipos de ações de saúde são financiados de modo predominante pelo setor público. Os orçamentos públicos e os seguros sociais são responsáveis por $94 \%$ dos gastos com medidas de prevenção e orientação, $76 \%$ das despesas com tratamentos, $87 \%$ daquelas com atenção hospitalar e $56 \%$ das despesas com reabilitação e auxílio-doença. Já as despesas com formação de pessoal e pesquisa médica são exclusivamente públicas (StBA, 1997).

A proporção dos gastos públicos aumentou de modo gradual, desde os anos 70 , tendência que permanece nos anos 90 . Maior participaçāo dos gastos públicos no conjunto das despesas com saúde resultou principalmente da crescente participação do GKV no financiamento e da reduçāo da participação direta dos empregadores.

Os gastos privados correspondem às despesas despendidas por empregadores, usuários no ato da utilização e seguros privados (tabela 16). Entre os gastos privados destaca-se a participaçāo do empregadores. Em 1994, as despesas de empregadores públicos e privados com a manutenção e recuperação da saúde de seus trabalhadores, sem considerar suas parcelas de contribuição aos seguros sociais, equivaleram a $14,7 \%$ do total dos gastos em saúde (70 bilhōes de marcos). ${ }^{183} \mathrm{~A}$ maioria desses gastos, cerca de $70 \%$, foram despendidos na forma de pagamento de salários nas seis primeiras semanas de doença $\left(49,4\right.$ bilhōes de marcos). ${ }^{184}$

É marcante a alteração da participação dos empregadores no financiamento dos gastos em saúde. As despesas diretas a seu encargo (sem incluir as contribuições sociais) evoluíram mais lentamente do que todas as outras fontes desde os anos 70. Enquanto os gastos do GKV aumentaram 7,4 vezes entre 1970 e 1994, as despesas diretas dos empregadores subiram 3,7 vezes (StBA, 1996). Um dos

18a Quando computadas as contribuiçōes para os seguros sociais, os gastos dos empregadores correspondem a $39 \%$ do total das despesas com saúde (StBA, 1997).

$184 \mathrm{O}$ restante das despesas foi realizado na forma de: ajuda para tratamento de saúde de seus empregados (12,3 bilhões de marcos) pelos empregadores públicos; aposentadorias precoces por invalidez para servidores públicos $(4,8$ bilhôes), assim como 2,1 bilhões para o financiamento dos serviços de saúde (Gesundheitsdienst) das empresas (StBA,1996 e 1997). 
motivos para a participação decrescente dos empregadores no financiamento direto do conjunto dos gastos em saúde foi a diminuiçāo da importância dos gastos com transferências financeiras no conjunto dos gastos em saúde.

Além das contribuições aos seguros sociais e de saúde, públicos ou privados, estima-se que os orçamentos domiciliares são responsáveis por $7,7 \%$ do conjunto dos gastos de saúde despendidos por meio do pagamento direto de despesas de saúde. A participação direta dos domicílios privados é importante para medicamentos e outros métodos terapêuticos e de ajuda e próteses dentárias. Estima-se que os indivíduos pagam diretamente cerca de um quarto dos medicamentos e mais de um terço das próteses dentárias. Os domicílios privados cobrem diretamente apenas $16 \%$ da atenção médicoodontológica ambulatorial e participam da atenção hospitalar de modo mínimo. Menos de $1 \%$ da atenção hospitalar é paga diretamente pelos doentes no ato da utilização.

Já as despesas dos seguros privados correspondem a apenas $6 \%$ do total de gastos com saúde. A participação dos gastos por conta dos domicílios privados, tanto para aqueles intermediados pelos seguros privados de saúde como para aqueles diretamente desembolsados pelos indivíduos, sofreu redução nos anos 70 e, a partir dos anos 80 , aumentou de forma leve, retornando em 1994 próximo ao nível de 1970 (tabela 16). ${ }^{185}$

A análise da participação de diferentes fontes de financiamento nos gastos totais em saúde, suas parcelas públicas e privadas, permite a observação da grande importância do GKV na garantia dos cuidados de saúde e possibilita o debate inicial acerca da tese da tendência à privatização dos gastos e da proteção à saúde.

Se analisados os dados apenas a partir de 1980, pode-se apontar leve tendência à privatizaçāo dos gastos em saúde. Os níveis de participaçāo dos gastos diretos dos domicílios e com os seguros privados alcançados em 1994, porém, são similares àqueles do período de expansão da proteção social. Além disso, os gastos sob encargo direto dos domicílios privados sofreram aumento menos acelerado do que o conjunto dos gastos em saúde (StBa, 1997). Assim, embora se observe leve aumento da participação dos domicílios privados no total de gastos em saúde ( $3 \%$ a $4 \%$ ), a tese da privatização progressiva dos gastos em saúde, segundo estes dados, não pode ser corroborada.

18.5 O mcsmo pode ser observado quando computados apenas os gastos com consumo médicosanitário e excluídas as transferências financeiras (Schneider et al., 1995). 


\section{Gastos do Seguro Social de Doença Alemão (GKV)}

A evolução dos gastos do Seguro Social de Doença alemão (GKV) reflete seu processo de desenvolvimento caracterizado por estabilidade e contínua expansão. Expansão em duplo sentido: de cobertura, por meio do processo de inclusão progressiva de trabalhadores de novos ramos da economia, característica geral da evolução dos sistemas de proteção social constituídos segundo os princípios de seguro social, e de ampliação do catálogo de açōes e benefícios. A análise de seus gastos por setores de atenção permite visualizar a ampliação progressiva do catálogo de açōes e benefícios e, ao mesmo tempo, os efeitos das medidas de contenção.

Em 1998, os gastos totais ${ }^{186}$ do GKV na Alemanha como um todo foram de 248 bilhões de marcos (US $\$ 146$ bilhõcs). Destes, $83 \%$ corresponderam a gastos da região ocidental, que foram de 206 bilhões de marcos (US $\$ 122$ bilhōes). Nessa mesma região, $87 \%$ dos gastos destinaram-se ao pagamento de ações médico-sanitárias, $8 \%$ a transferências financeiras aos segurados e $5 \%$ a despesas administrativas (www.bmgesundheit.de). ${ }^{187}$

$\mathrm{Na}$ regiāo oriental, os gastos foram de 42 bilhọ̃es de marcos, sendo 39 bilhões utilizados $\mathrm{em}$ ações de saúde e 2,4 bilhões em auxílio-doença. A diferença no volume de gastos entre as duas regiões é decorrência principalmente do menor número de segurados da região oriental do que de despesas inferiores por segurado na região. Os gastos por segurado, em 1995, foram de 3.454 DM na região oriental e de $3.700 \mathrm{DM}$ na região ocidental, diferença de apenas $7 \% .{ }^{188}$

As diferenças de gastos entre as duas regiōes diminuíram rapidamente desde 1991 , tendo os dispêndios da região oriental se aproximado do padrão da região ocidental. Após a unificação, a evolução dos gastos do GKV para todos os setores de atenção e benefícios na regiāo oriental foi muito mais acelerada do que na região ocidental, em razão do processo de adequação e acomodação ao padrāo de ações e gastos ocidentais.

Observou-se um processo de acomodação tanto da oferta como da demanda. A oferta diversificou-se e organizou-se para produzir c contabilizar os gastos no padrão ocidental, os profissionais de saúde ampliaram prescrições e os segurados tomaram conhecimento dos novos benefícios e açōes disponíveis, passando a demandá-los.

186 Os gastos totais do Seguro Social de Docnça, além dos gastos com ações de saúde e benefícios em dinheiro, incluem os gastos administrativos e outros, como transferências linanceiras entre as Caixas para a compensação da estrutura de riscos.

187 Benefícios em espécie: auxílio-doença, auxílio-maternidade, auxílio-parto e auxílio-funeral.

188 Em 1991, os gastos por segurado na regiāo oriental correspondiam a cerca de $60 \%$ dos gastos da região ocidental (BMG, 1996). 


\section{Distribuição dos gastos do $G K V_{\text {por }}$ setores de atenção: região ocidental}

Os gastos do Seguro Social de Doença concentram-se em açõcs curativas individuais, notadamente hospitalares e ambulatoriais. ${ }^{189}$ As medidas de promoção $\mathrm{c}$ prevenção representam pequena parcela dos mesmos. A atençāo ambulatorial - médico-odontológica e por profissionais diversos - é responsável por $26 \%$ dos gastos, e a atenção hospitalar, por 34 \% (StBA, 1996). A seguir são analisados os gastos do GKV por setores de atenção e benefícios sclccionados e sua evoluçāo nas últimas décadas (tabela 16 e gráfico 3).

Tabela 16 - Distribuição dos gastos do GKV por setores de atenção e benefícios selecionados. Alemanha, região ocidental - 1960-1995

\begin{tabular}{lrrrrrrrrrrrr}
\hline Atenção & 1960 & 1970 & 1975 & 1980 & 1985 & 1990 & 1991 & 1992 & 1993 & 1994 & 1995 \\
\hline Hospitalar & 17,5 & 25,2 & 30,1 & 29,6 & 32,2 & 33,2 & 32,4 & 32,1 & 33,9 & 34,4 & 34,0 \\
Ambulatorial & 20,9 & 22,9 & 19,4 & 17,9 & 18,1 & 18,2 & 17,6 & 17,2 & 18,0 & 17,4 & 17,2 \\
Farmacceutica & 12,2 & 17,7 & 15,3 & 14,6 & 15,3 & 16,3 & 16,1 & 16,1 & 13,8 & 12,8 & 13,2 \\
Auxílio-docnça & 30,0 & 10,3 & 8,0 & 7,7 & 5,9 & 6,5 & 7,5 & 7,3 & 7,3 & 7,3 & 8,0 \\
Outros meios* & 2,4 & 2,8 & 4,4 & 5,7 & 6,0 & 6,3 & 6,4 & 6,5 & 6,8 & 7,2 & 7,5 \\
Odontológica & 5,2 & 7,2 & 7,1 & 6,4 & 6,0 & 6,1 & 6,0 & 6,1 & 6,3 & 6,1 & 5,9 \\
Próteses dent. & 3,0 & 3,5 & 7,2 & 8,6 & 7,1 & 3,6 & 3,7 & 4,1 & 3,0 & 3,2 & 3,3 \\
Maternidade** & 4,4 & 4,6 & 2,9 & 3,5 & 2,5 & 2,4 & 2,2 & 2,1 & 2,2 & 2,1 & 2,0 \\
Depend. sevcra & - & - & - & - & 0,1 & 1,2 & 1,4 & 1,5 & 1,6 & - & - \\
Outros & 4,4 & 5,8 & 5,6 & 6,0 & 6,9 & 7,3 & 6,9 & 7,1 & 7,2 & 7,9 & 8,9 \\
\hline Total & 100 & 100 & 100 & 100 & 100 & 100 & 100 & 100 & 100 & 100 & 100 \\
\hline
\end{tabular}

* Outros meios: inclui outros métodos de cura e meios de ajuda. ** Maternidade inclui: açōes médicas c transferências financeiras.

Fonte: BMG, 1996.

189 A rubrica prevenção e ajuda/orientação é responsável por $5 \%$ dos gastos (SıBA, 1996). 


\section{Atenção hospitalar}

A importância da atenção hospitalar na atenção médica reflete-se na sua participação nos gastos. Atualmentc, cstc é o setor da atenção que despende maior quantidade de recursos. Os gastos com atenção hospitalar tiveram aumento progressivo de sua importância, em espccial, até 1975, quando alcançaram $30 \%$ do conjunto das despesas do GKV (gráfico 3). ${ }^{190}$

Em 1995, 34\% dos gastos destinaram-sc ao pagamento da atenção hospitalar proporcionada aos segurados do GKV. $\mathrm{Na}$ última década, os gastos com este setor aumentaram de modo mais acelerado $(62,1 \%)$ do que as despesas do GKV como um todo $(57,9 \%) .{ }^{191}$ Por sua elevada participação, o sctor hospitalar é tido como o principal responsável pclos 'gastos crescentes' pelos defensores da contenção de gastos na Alemanha.

\section{Gráfico 3 - Distribuição dos gastos do GKV por setores de atenção e benefícios selecionados. Alemanha, região ocidental - 1960-1995}

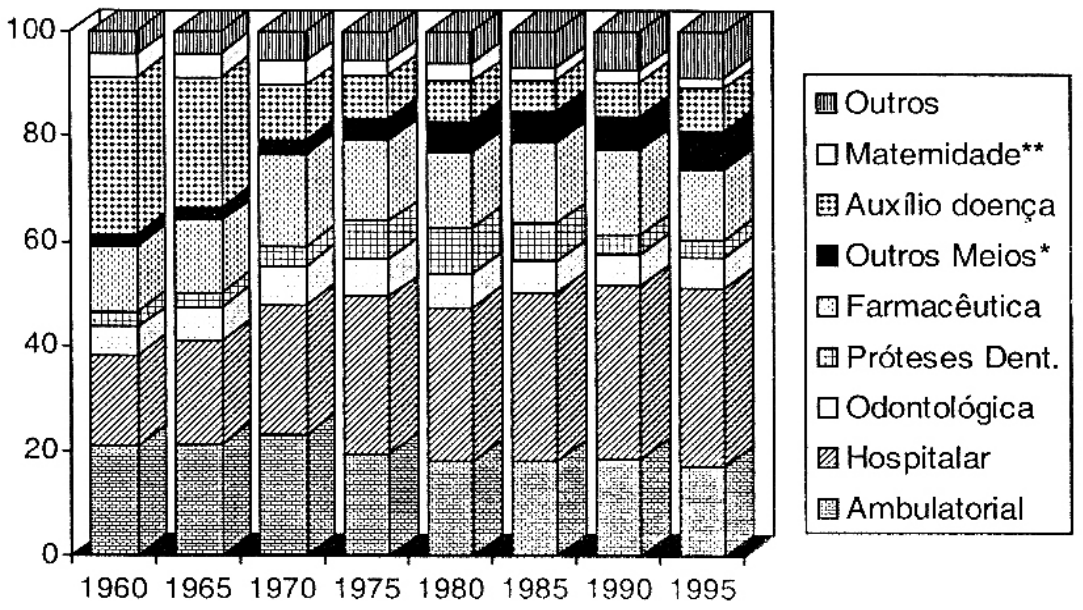

*Outros mcios: inclui outros método de cura e mcios de ajuda. ** Matemidade inclui: açõcs médicas e transferências financciras.

Fonte: BMG, 1996.

190 No período de 1970 a 1975 , por iniciativa da coalizão social-democratas/liberais entāo no poder; foi deslanchado um processo de modernização e recuperação da estrutura de atcnção - novos investimentos e ampliaģão de pessoal -, em particular, no setor hospitalar. Os gastos hospitalares triplicaram no período. Como grande parte da modernização foi financiada pelas diárias hospitalares, quase $\mathrm{cm}$ sua totalidade pagas pelas Caixas, o impacto sobre as taxas de contribuição foi imediato.

19! A participação dos gastos hospitalares no conjunto dos gastos $\mathrm{cm}$ sańde diminuiu levemente na maioria dos países da OECD cntre 1980 c 1993, cm particular como resultado de deslocamento de ações para o setor ambulatorial. 


\section{Atenção médica ambulatorial}

A participação dos gastos ambulatoriais no conjunto das despesas do Seguro Social de Doença, que chegou a atingir 23\% em 1970, apresentou gradual redução durante os anos 70 . Desde 1980, tem-se mantido estável, oscilando entre $17 \%$ e $18 \%$ (gráfico 4). Em 1998, correspondia a 17,8\% do total de gastos. Esta estabilidade da participação dos gastos médicos ambulatoriais deve-se tanto à participação progressivamentc maior de outros setores da atenção quanto à evolução moderada de scus gastos, em geral inferior à média anual para o GKV.

A participação estável dos gastos com atenção médica ambulatorial no conjunto das despesas do GKV é utilizada, pela corporação médica, como argumento de não neccssidade de inclusāo do setor ambulatorial em medidas de contençāo, no que tiveram parcial sucesso. Em 1989 e 1993, anos de entrada em vigor de leis de contenção, enquanto o GKV como um todo reduziu seus gastos, aqueles com atençāo médica ambulatorial continuaram a crescer, ainda que de modo um pouco mais lento.

Gráfico 4 - Participação dos gastos ambulatoriais e hospitalares no conjunto dos gastos do GKV - Alemanha Ocidental - 1960 - 1995

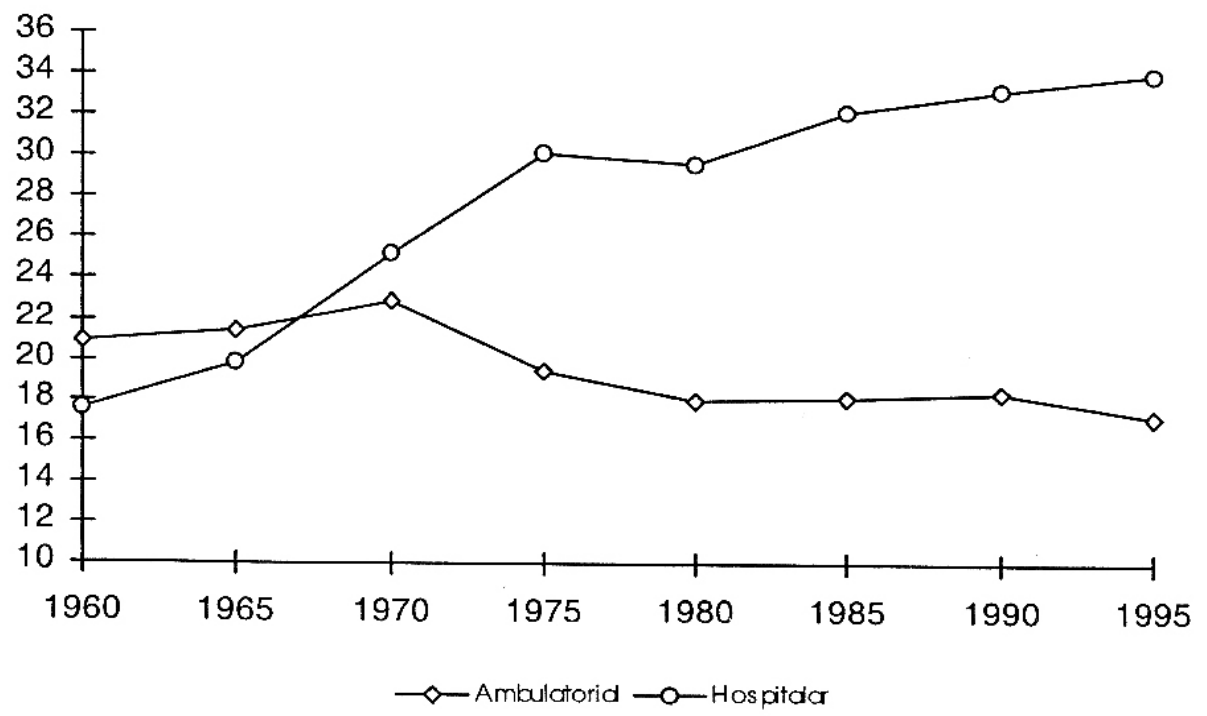

Fonte: BMG, 1996. 


\section{Atenção odontológica}

Os gastos com atenção odontológica na Alemanha são elevados. ${ }^{192} \mathrm{Em}$ 1995, a atenção odontológica em seu conjunto representou $9,2 \%$ dos gastos do GKV. Sua participação, que chegou a $15 \%$ em 1980, tem decrescido a partir de então por conta de restrições feitas, em particular, para as próteses. Estas, desde 1993, correspondem apenas a um terço dos gastos com assistência odontológica.

Excluídas as próteses dentárias, a participação dos gastos com atenção odontológica no conjunto das despesas do GKV tem se mantido em torno de $6 \%$ desde os anos 80, tendo sua evolução acompanhado o ritmo do conjunto dos gastos.

O acesso a próteses dentárias foi ampliado na segunda metade dos anos 70 , o que produziu forte elevação de sua participação no conjunto dos gastos, chegando a $8,6 \% \mathrm{~cm}$ 1980. Entre 1975 e 1985, os gastos com próteses representaram mais de $50 \%$ da atenção odontológica como um todo. Na última década, por conta de restriçōes - via cortes e aumento da participação dos usuários - os gastos com próteses dentárias oscilaram fortemente, atingindo a mais baixa taxa de crescimento no somatório da década. ${ }^{193}$

\section{Assistência farmacêutica}

Os gastos com assistência farmacêutica $\mathrm{em} 1995$ foram responsáveis por $13,2 \%$ do conjunto dos gastos. Desde os anos 70, os gastos com medicamentos ocupam o terceiro lugar em importância na participação, após os setores hospitalar e ambulatorial. Na ultima década, a participação dos gastos com medicamentos no conjunto dos gastos do GKV aumentou, de modo gradual, até 1992. Em 1993, esta participação diminuiu, passando de 16,1 para 13,8, em virtude da redução real em $19 \%$ do montante despendido com medicamentos no ano, devido à Lei da Estrutura da Saúde (GSG), que fixou teto orçamentário para prescriçōes e impôs sanções aos médicos, caso fosse ultrapassado. Este mecanismo surtiu efeito ainda em 1994. No ano seguinte, as sançōes, por influência da corporação médica, foram afrouxadas, e os gastos com medicamentos voltaram a aumentar mais do que o conjunto dos gastos. ${ }^{194}$

192 Estima-se que os gastos totais com atengăo odontológica na Alemanha sejam dos mais altos do mundo. Em 1990 representavam 0,9\% do PNB, encquanto nos EUA eram de 0,62\% e na GrīBretanha de $0,32 \%$ do PNB. Os gastos per capita calculados segundo presos com paridade de poder de compra eram o dobro dos da União Européia e 50\% mais alıos do que nos EUA (BMAS, 1994).

193 A observação da evolução dos gastos com próteses dentárias mostra bem os efeitos de contenção das Leis da Reforma da Saúde, em 1989, c da Lei da Estrutura da Saúde, em 1993. As restrições impostas produziram diminuição imediata de $50 \%$ e $28 \%$, respectivamente. Podese observar também uma reação preventiva que provocou antecipação de gastos. Em 1988, o anúncio de restriçōes desencadeou corrida aos consultórios, provocando forte aumento no volume de gastos com próteses no ano.

19. O mesmo ocorreu em 1996. O controle de gastos no setor é particularmente difícil por conta da forte influência da indústria farmacêutica, que conseguiu vetar a elaboração de listas positivas (Steflen, 1996a). 
A assistência farmacêutica é apontada como o setor da atenção em que a introdução de medidas de controle de qualidade melhor poderiam ter efeitos de eficiência - reduzindo gastos, sem produzir restrições na atenção garantida. Em 1995, as prescrições de medicamentos de efeitos duvidosos ou não comprovados ${ }^{195}$ foram responsáveis por $23 \%$ dos gastos com medicamentos e outros produtos distribuídos pelas farmácias, alcançando faturamento aproximado de 7 bilhões de marcos, o montante do déficit do Seguro Social de Doença no ano para a Alemanha como um todo (Gerlinger \& Schönwälder, 1996; Schwabe \& Paffrath, 1996). ${ }^{196}$

\section{Outros meios de tratamento e ajuda}

Os outros meios - métodos terapêuticos (Heilmittel) e meios de ajuda (Hillsmittel) - envolvem grande diversidade de ações, com evolução diferenciada de gastos. Em seu conjunto, esta rubrica foi responsável, em 1995, por 7,5\% dos gastos do GKV.

Nas últimas décadas, estas despesas cresceram sempre acima da média do conjunto dos gastos. Isto produziu expressivo aumento, mais de $70 \%$, da participação desta rubrica no conjunto dos gastos do GKV, nos últimos vinte anos. $\mathrm{Na}$ última década, estas foram as despesas de crescimento mais acelerado. Este crescimento é decorrente da inclusão progressiva de novas ações terapêuticas e da difusão das referidas profissōes, que disponibilizou o acesso a um maior número de segurados, bem como da maior sofisticação de meios de ajuda utilizados.

O baixo acréscimo de gastos com outros meios verificado em 1993 foi conseqüência da GSG, que fixou tetos máximos para a prescrição de outros métodos terapêuticos pelos médicos, idêntica medida utilizada para o controle de medicamentos. Desde 1994, têm sido negociados tetos máximos de gastos para estas ações em nível estadual, juntamente com os gastos para medicamentos.

\section{Auxílio-doença}

Com o processo de expansão do GKV e ampliação progressiva da cesta de benefícios cobertos, os gastos com transferências financeiras perderam importância. Sua participação no conjunto das despesas do GKV decresceu por conta tanto de evolução menos acelerada que a do conjunto dos gastos, como em virtude da ampliação do catálogo de ações médico-sanitárias. A maior alteração ocorreu nos anos 60 , quando a participação do auxílio-doença passou de $30 \%$, em 1960, para 10,3\%, em 1970. Em 1980, os gastos com auxílio-doença atingiram

\footnotetext{
195 Associaçōes espúrias, expectorantes, medicamentos de uso externo para varizes e reumatismo, estimuladores da circulação cerebral etc.

196 Não é possível afirmar que apenas o corte destes medicamentos evitaria todo o déficit, pois nāo foi calculada a influência do co-pagamento nestes dados, pois as receitas com co-pagamento não foram subtraídas.
} 
seu nível mais baixo de participação: apenas 5,9\%. Nos anos 90 , essa proporção voltou a subir levemente, alcançando $8 \%$ em 1995.

Essa recente mudança não passou despercebida à coalizão governamental, que decretou, apesar dos protestos, a redução do benefício $\mathrm{cm}$ setembro de 1996 ; uma das medidas do Sparpaket. ${ }^{197}$

\section{Dependência severa}

As açōes domiciliares ou em regime de intcrnaçāo relativas a cuidados de longa duração foram introduzidas no catálogo do GKV em 1989; contudo, com a criação de um ramo de seguro social específico para estes cuidados, as respectivas despesas com segurados por dependência severa passaram a ser contabilizadas no novo ramo do seguro social desde o segundo semestre de 1995.

\section{Gastos administrativos}

A preocupação a respeito dos gastos com administração tem adquirido maior importância com o avanço das medidas de contenção e da competição entre as Caixas. Os gastos administrativos seriam mais diretamente influenciáveis pelas próprias Caixas por meio da adoção de medidas gerenciais. A atuação mais cficiente das Caixas no sentido do controle de gastos administrativos poderia colocálas $\mathrm{em}$ vantagem na competição por segurado.

Os gastos do GKV com administração apresentaram evolução similar à do conjunto de gastos, mantendo quase constante seu percentual de participação em torno de $4 \%$ a $5 \%$ dos gastos totais do GKV desde os anos 70 . Sua maior participação ocorreu em 1990 , quando alcançou 5,14\%. ${ }^{198}$

A partir do cotejo dos gastos administrativos dos seguros privados, é possível estimar os gastos administrativos das Caixas como nāo excessivos. Os gastos administrativos dos seguros privados de saúde na Alemanha, em 1992, representaram $15 \%$ das receitas com prêmios c $12,7 \%$ do conjunto de suas receitas. ${ }^{199}$

$\mathrm{O}$ aumento dos gastos administrativos é tido como uma das prováveis conseqüências inadequadas da maior competição entre as Caixas, uma vez que

197 Para maiores detalhes acerca do Sparpaket, vide Stotz \& Giovanella, 1996.

198 Os gastos administrativos variam cntre as Caixas e regiöes. Em 1995, os gastos administrativos das Caixas Locais foram de $5,3 \%$, na região ocidental, e de $6,4 \%$, na regiäo oriental (AOK, 1995). Para Techniker Krankenkasse, uma das Caixas Substitutas para Empregados, de clientela restrita e das mais ricas, estes gastos foram de $4,3 \%$.

199 Em cotejo internacional com base em estimativas feito pela OECD, a participação dos gasıos administrativos no total de gastos em saúde na Alemanha seria das mais altas entre os países da OECD. Os autores, porém, chamam a atençāo para o provável nível mais elevado deste tipo de gastos nos EUA e das dificuldades para a confrontação (OECD, 1995a). Nos EUA, em 1987, os gastos administrativos dos seguros privados eram de $11,7 \%$ (Schwartz \& Busse, 1994). Donaldson \& Gerard (1992) referem para o mesmo caso $13,4 \%$. 
esta, mais do que estimular o aumento da eficiência, poderia levar a acréscimo de gastos administrativos das Caixas, em especial com marketing e serviços personalizados de atendimento ao cliente.

\section{GKV: pelação entre receitas e despesas}

A justificativa imediata das medidas de contenção reside nos reiterados déficits apresentados pelas Caixas, uma vez que as despesas têm crescido com freqüência mais rapidamente do que as receitas de contribuição. $\mathrm{Na}$ última década pode-se observar ciclos bianuais de déficits e superávites resultantes das reformas introduzidas. Déficits recorrentes, ao final da década de 80, desencadearam a Lei da Reforma da Saúde, de 1988, cujos efeitos se fazem notar nos dois anos imediatamente posteriores.

Em 1991 e 1992, os gastos voltam a superar as despesas. As medidas da Lei da Estrutura da Saúde, implementadas no início de 1993, produziram redução dos gastos em 1993 e superávits neste ano e no subseqüente. Em 1995 e 1996 houve novos déficits e foram implementadas medidas de contenção no segundo semestre de 1997. Nesse ano, seus efeitos sobre a contenção já puderam ser avaliados. Após um déficit de quase 7 bilhões de marcos no ano de 1996, o GKV fechou 1997 com superávit de 1,1 bilhões.

Tabela 17 -Seguro Social de Doença alemão (GKV). Receitas, despesas e saldo financeiro. Região ocidental - 1970-1997. Saldo financeiro. Região oriental - 1991-1997*

\begin{tabular}{ccccc|c}
\hline Ano & Reccitas & Despesas & Saldo Oeste & Saldo Lestc & Saldo Total \\
\hline 1970 & 26.116 & 25.179 & 937 & - & \\
1980 & 88.452 & 89.834 & -1.382 & - & \\
1985 & 11.831 & 114.108 & -2.277 & - & \\
1986 & 118.507 & 119.867 & -1.361 & - & \\
1987 & 125.074 & 124.997 & 77 & - & \\
1988 & 132.639 & 134.376 & -1.737 & - & \\
1989 & 139.682 & 129.927 & 9.755 & - & \\
1990 & 147.753 & 141.654 & 6.099 & - & \\
1991 & 154.221 & 159.814 & -5.593 & 2.773 & -2.820 \\
1992 & 167.778 & 176.876 & -9.098 & -256 & -9.354 \\
1993 & 184.421 & 175.362 & 9.059 & 1.355 & 10.414 \\
1994 & 194.181 & 192.120 & 2.061 & 116 & 2.177 \\
1995 & 212.233 & 217.352 & -5.119 & -1.836 & -6.955 \\
1996 & 219.700 & 224.340 & -4.640 & -2.140 & -6.780 \\
1997 & 220.750 & 219.350 & 1.400 & -300 & 1.100 \\
\hline
\end{tabular}

*Em milhões de marcos correntes.

Fonte: BMG, 1996 T.10.9; para 1996 c 1997, http://www.bmgesundheit.de em 11.06 .98$. 
Os déficits, assim como a evolução dos dispêndios por item, são diferenciados entre as Caixas. Em 1996, os gastos por contribuinte nas Caixas Substitutas aumentaram $3,6 \%$ na região ocidental e $3 \%$ na região oriental, enquanto suas receitas de contribuiçāo cresceram apenas $1,1 \%$. Os gastos das Caixas Locais tiveram aumento maior: $6,4 \%$ na região ocidental e $2,4 \%$ na oriental, contra pequeno aumento de receitas de contribuição de $0,7 \%$ e 1,5\%, respectivamente.

Recentemente, o Fundo de Compensação da Estrutura de Riscos dos Segurados entrou no rol dos motivos de déficits. As Caixas, obrigadas a fazer repasses para o Fundo, responsabilizam-nos por suas dificuldades financeiras. Em 1996, as Caixas Substitutas apresentaram déficit de 3,3 bilhōes de marcos (700 milhões na Região Leste), tendo participado com 16 bilhões na compensação financeira de riscos. As Caixas Locais, em decorrência das diferenças na estrutura de riscos de seus segurados, receberam montante similar e apresentaram déficit de 2 bilhōes. As Caixas de Empresas, que transferiram 1,4 bilhões para o fundo de compensação, alegam que estas transferências seriam responsáveis por seu déficit de 400 milhões de marcos (FR.04.03.97).

\section{O Problema dos Gastos em Saúde: explosão dos custos ou eposão das receitas?}

O debate sobre o problema dos gastos no setor saúde é impregnado pela instrumentalizaçāo política na apresentação de dados. Kühn (1995a) se pergunta como é possível utilizar a metáfora "a explosāo de custos", que sugere acontecimentos catastróficos por um período de vinte anos. "Como alguma coisa pode explodir durante 20 anos?” A utilização desta metáfora, por si só, sugere certa arbitrariedade.

Se analisados os artigos que difundiram a "explosão de custos" na Alemanha, na metade dos anos 70, a 'explosão' pode ser em parte atribuída a dois simples artifícios estatísticos. Um deles é o valor do ano-base selecionado. Quanto mais baixo o valor do ano-base, maior o crescimento. O outro é a relação entre as ordenadas. Quanto menor o intervalo na escala utilizada no eixo das ordenadas e menor o espaçamento nas abcissas, mais abrupta parcce ser a subida da curva. Assim, uma funçāo linear levemente ascendente foi apresentada como tendência exponencial (Kühn, 1995a).

O aumento dos gastos em saúde nas últimas décadas (de 1980 e 1990) foi gradual. Apenas no início dos anos 70 , verificou-se uma evolução abrupta dos 
gastos de saúde em curto espaço de tempo. Não obstante, a metáfora da explosão de custos nāo seria adequada mesmo neste caso.

O expressivo aumento dos gastos das Caixas entre 1970 e 1975 foi decorrente da expansão da atenção garantida pelas Caixas por meio da ampliação do catálogo obrigatório e modernização hospitalar (Alber, 1992); tanto que o GKV passou a responder por 44\% das despesas totais com saúde em 1975, participação quase um terço maior do que em 1970 (35\%) (Stegmüller, 1996a).

A dinâmica expansiva de gastos do GKV cntre 1970 e 1975, para Stegmüller, deve ser compreendida no contexto de ampliação da proteção à saúde do período 1965-1975, quando foi garantida, em alto nível, a maior parte da população. ${ }^{200}$ Uma dinâmica específica que não se repetirá, pois o ciclo da expansāo se esgota necessariamente com a universalização - a garantia real da protcção para a maior parte da população com a oferta e o accsso a serviços em qualidade e quantidade suficientes. ${ }^{201}$

Se analisada a evolução da participação dos gastos em saúde no PNB após este período, observa-se certa estabilização dos gastos do GKV. De fato, o que provocou a discussão sobre a contenção foi o aumento contínuo das taxas de contribuição do Seguro Social de Doença. Nos últimos vinte anos, as taxas médias de contribuição aumentaram gradualmente, tendo crescido três pontos percentuais. Passaram de 10,47\%, em 1975, para 13,45\%, em 1996. Desde os anos 70, embora o objetivo político-econômico das medidas de contenção de gastos em saúde tenha sido a estabilização das taxas de contribuição, csta não foi atingida.

No debate sobre as possibilidades de melhora da posiçāo da Alemanha na competiçāo econômica internacional (Standort Deutschland), a diminuição dos custos sociais do trabalho, entre os quais se incluem as contribuições para o Seguro Social de Doença, tem sido considerada um dos fatores centrais. Daí a ênfase na estabilização/redução das taxas de contribuiçāo (Deppe, 1996a). Para Kühn (1995), a tematização do problema das contribuiçōes como 'explosão de custos' levou a uma tipologia de soluções voltadas para cortes nos gastos e concentradas nos pacientes. Se a questão fosse o alcance de maior eficiência - redução de custos das ações de saúde - e elevação da economicidade do sistema, as soluções centrar-seiam no controle dos prestadores de serviços e dos produtores de insumos, principais responsáveis pelos incrementos de gastos.

200 Os anos 60, até o início dos anos 70, correspondem a um período de forte expansão cm diversas árcas sociais. Na Alemanha, entre 1960 e 1975, o conjunto dos gastos sociais cresceu em 11 pontos percentuais $\mathrm{cm}$ relação ao PIB (Behagel, 1994).

201 Como conseqüência dessa expansão, as taxas de contribuição passaram de $8,2 \%$, no ano de 1970 , para $10,4 \%$, em 1975 , e a participação dos gastos do GKV no PNB aumentou de 3,7 para $5,7 \%$ no mesmo período. 


\section{Evolução das receitas: participação da renda do trabalho assalariado na economia}

O problema não seria tanto de incremento de gastos e mais de crosão das receitas. A modalidade de financiamento do sistema alemão, por meio da arrecadação de contribuiçōes, faz com que as receitas das Caixas - limitadas aos rendimentos do trabalho assalariado - estejam imediata e diretamente ligadas à conjuntura econômica e à situação do mercado de trabalho.

Para diversos autores, o aumento das taxas de contribuição foi essencialmente condicionado pelo descompasso cntre a evoluçāo do PNB e os rendimentos do trabalho assalariado, o qual se expressa na reduçāo da participação da cota de salários na economia popular (Volkscinkommen) ${ }^{202}$ (Kühn, 1995b; Deppc, 1996b; Steffen, 1996a; Gerlinger \& Schönwälder, 1996; Stegmüller, 1996a). A economia popular corresponde, em termos simples, à parcela do PNB constituída pela soma de todos os rendimentos provenientes de salários, ordenados, juros, aluguéis e lucros. A cota de participação dos salários na renda popular aumentou continuamente até o início dos anos 80, alcançando o scu ápice em 1982 e, a partir de então, tem declinado gradualmente, com uma única exceção.

A participação dos rendimentos do trabalho assalariado na renda nacional foi, em 1982, de 76,9\% e caiu, cm 1993, para 72,1\%. Em 1995, esta proporçāo da renda nacional caiu novamente para $69 \%$, cstando atualmente abaixo do nível dos anos 70 (Steffen, 1996a). Este declínio da participação da massa salarial na renda nacional tem como contrapartida o aumento da participação das rendas decorrentes da atividade empresarial, do trabalho autônomo e de capital. ${ }^{213}$

Semelhante diminuição da participaçāo dos rendimentos do trabalho assalariado na renda popular ocorre mesmo quando sāo excluídas diferenças decorrentes da mudança da cstrutura de ocupação para o cálculo da cota de participação dos rendimentos do trabalho assalariado (Schäfer, 1996a e 1996b). ${ }^{201}$

202 Brutto-Lohnquote: participação da renda proveniente do trabalho assalariado, não autônomo - inclusive contribuições dos empregadores para o seguro social -, na economia popular em percentagem. A economia popular (Volkscinkonmen) inclui rendimentos pessoais provenientes do trabalho assalariado e autônomo, além de ativịdades empresariais, e corresponde a mais de $70 \%$ do PNB. No Brasil, a participação da massa salarial no PIB é menor que $30 \%$ (FSP.02.05.98:1-3).

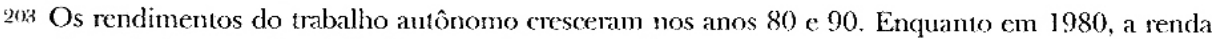
disponível em um domicílio de um autônomo era duas vezes àquela de um operário, cm 1994 esta relação havia subido para três vezes. Paralelanente, aumentaram os lucros e foram reduzidos os impostos sobre as rendas provenientes da atividade empresarial e elcvados os impostos sobre os rendimentos do trabalho, tudo isto contribuindo para a redução da cota de rendimentos do trabalho assalariado, base para desconto das contribuições (Stegmüller,1996: 69).

201 Poder-se-ia supor que a participação da renda do trabalho assalariado teria sido reduzida por um aumento do trabalho autônomo, por cxcmplo. Ao considerar-se mudanças na cstrutura da ocupação, este argumento perde validade. 
Desde o início dos anos 80 , o volume total dos salários tem crescido mais lentamente do que o PNB, o que se expressa na diminuição da cota de participação dos rendimentos do trabalho assalariado na renda popular. Se a participação da renda do trabalho assalariado no PNB diminui, significa que a potencialidade de financiamento do Seguro Social de Doença não aumenta proporcionalmente conforme o aumento do PNB.

Assim, mesmo que os gastos em saúde evoluam no mesmo ritmo de crescimento do PNB, situação que pode ser amplamente desejável, as taxas de contribuição terão de ser majoradas. Ou seja, com a diminuição relativa da renda do trabalho assalariado, a base financeira do sistema GKV - centrada nas contribuiçōes do trabalho assalariado - sofreu erosão. A manutenção de receitas condizentes a um volume de gastos iguais ou crescentes implicou o aumento das taxas de contribuiçāo, uma vez que o funcionamento das Caixas tem, como princípio, o equilíbrio entre despesas e receitas.

Tabela 18 - Cota de participação dos rendimentos do trabalho assalariado na economia popular. Alemanha Ocidental - 1960-1995

\begin{tabular}{cc}
\hline Ano & Salários \\
\hline 1960 & 60,1 \\
1970 & 68,0 \\
1975 & 74,2 \\
1980 & 75,8 \\
1985 & 73,0 \\
1990 & 69,6 \\
1995 & 69,0 \\
\hline
\end{tabular}

Fonte: Kühn, 1995b; Deppe, 1998a; Steffen,1996a.

Nesse sentido, a argumentação de empresários de que os custos do trabalho aumentaram por conta da elevaçāo das taxas de contribuição para os diversos ramos do seguro social, o que levaria à piora de sua posição na competitividade internacional, tem pouco fundamento. A cota de participação dos rendimentos do trabalho na renda nacional - salários mais contribuições sociais - tem diminuído, o que significa dizer que os custos totais do trabalho foram reduzidos, apesar da elevação das taxas das contribuiçōes sociais. A evolução real da renda do trabalho na última década tem sido modesta. Acordos coletivos têm sido fechados nos níveis de inflaçāo e índices maiores têm resultado, por vezes, de contrapartidas compensatórias para os empregadores. 
Importante fator adicional para erosão das receitas do Seguro Social de Doença (GKV) foi o aumento progressivo do desemprego. Enquanto na Alemanha Ocidental, em 1981, existiam 1,3 milhões de desempregados, essa população ultrapassara, em 1996, a casa dos 4 milhões em todo o país. Afora a redução da base de contribuição que os proventos menores implicam, a base de cálculo para as taxas de contribuição pagas pelo seguro-desemprego ao GKV foi diminuída.

$\mathrm{O}$ alto nível de desemprego na Alemanha, ao contrário da maior parte dos países da OECD, é fenômeno relativamente recente, em especial, da década de $90 .{ }^{205} \mathrm{~A}$ taxa de desemprego alemā, mesmo sendo mais baixa que nos outros países, encontra-se em alta desde a metade dos anos 80. Em março de 1997 estava em $9,7 \%$ e continuava a crescer. No início dos anos 90 (1990 a 1993), por conta do impulso decorrente da unificaçāo, as taxas de desemprego foram contidas. O maior número de postos de trabalho na Alemanha Ocidental foi atingido em 1992, quando 29,1 milhões de pessoas encontravam-se ocupadas, incluídos os autônomos. O problema do desemprego na região oriental é mais grave, pois a taxa de desemprego ultrapassa $20 \%$ em alguns dos cinco novos estados. Estima-se que, de 1989 a 1995, foram extintos 3,34 milhões de postos de trabalho na região oriental, ao passo que, no mesmo período, foram criados $800 \mathrm{mil}$ novos postos na regiāo ocidental (Bundosregierung, 1997b).

Diversas outras alterações no mercado de trabalho contribuíram para a * erosão de receitas do GKV. Além do desemprego crescente, o aumento da participaçāo dos trabalhadores por tempo parcial e das mulheres - grupos cujos salários são, em geral, mais baixos - no total de contribuintes compulsórios, também teve repercussões sobre o potencial de arrecadação do GKV.

Na região ocidental, a proporção de trabalhadores em tempo parcial entre a população ocupada com obrigatoriedade de asseguramento passou de $8 \%$, em 1980, para 12,8\%, em 1995. A proporção de mulheres, por sua vez, passou de 38,6\%, em 1980, para 42\%, em 1995 (BMAS, 1996a). Ao mesmo tempo, aumentou o número de relações de trabalho dispensadas de contribuições sociais (Schönbach, 1997:65).

Outros fatores que pesaram para essa situação foram os reajustes insuficientes dos tetos dos salários de contribuição e a transferência de ônus de outros ramos do seguro social para o GKV, em especial, da previdência e seguro-desemprego. Aspecto este, enfatizado por críticos das reformas propostas pela coalizão governamental liberal-conservadora.

205 Outra característica alemã é a baixa taxa de desemprego entre jovens. Graças ao sistema dual de formação profissional, nas empresas e escolas profissionais, a Alemanha apresenta a penúltima taxa dentre as mais baixas, 7,6\% para jovens de $15-19$ anos e $9,5 \%$ para menores de 25 anos, entre 19 países da OECD. Na Espanha estas taxas eram de $50 \%$ e $4.1 \%$ e na Itália $36 \%$ e 35\% (dados de 1995 e 1996) (Bundosregierung, 1997b). 
Tabela 19 -Taxas de desemprego em países selecionados - 1970-1997

\begin{tabular}{lrrrrrr}
\hline Países & $1970-1980$ & $1980-1990$ & 1994 & 1995 & 1996 & $1997^{*}$ \\
\hline Alemanha** & 2,5 & 5,7 & 8,4 & 8,2 & 9,0 & 9,7 \\
Bćlgica & 4,6 & 10,4 & 10,0 & 9,9 & 9,8 & 9,6 \\
Dinamarca & 4,3 & 7,4 & 8,2 & 7,2 & 6,9 & 6,3 \\
França & 4,1 & 9,0 & 12,3 & 11,7 & 12,4 & 12,5 \\
Grã-Bretanha & 3,8 & 9,5 & 9,6 & 8,8 & 8,2 & 7,3 \\
Itália & 6,5 & 9,3 & 11,4 & 11,9 & 12,0 & 12,2 \\
Japāo & 1,7 & 2,5 & 2,9 & 3,1 & 3,4 & 3,3 \\
Holanda & 3,9 & 9,9 & 7,1 & 6,9 & 6,3 & 5,7 \\
Norucga & 1,1 & 3,0 & 5,4 & 4,9 & 4,8 & 4,7 \\
Áustria & 1,8 & 4,2 & 3,8 & 3,9 & 4,4 & 4,4 \\
Sućcia & 2,1 & 2,4 & 9,8 & 9,2 & 10,0 & 10,9 \\
Suíça & 0,4 & 0,6 & 4,7 & 4,2 & 4,7 & 5,5 \\
Espanha & 5,2 & 17,9 & 24,1 & 22,9 & 22,2 & 21,4 \\
EUA & 6,2 & 7,0 & 6,1 & 5,6 & 5,4 & 5,2 \\
União Européia & 4,2 & 9,3 & 11,1 & 10,8 & 10,9 & 10,9 \\
\hline
\end{tabular}

*Relativo ao mês de março de 1997; todas as outras taxas são médias dos pcríodos. **A partir de 1994, as taxas se referem à Alcmanha como um todo.

Fontc: Eurostat, International Labour Officc c OECD apud Sozialpolitische Umschau, 1997: n.254.

Nos últimos anos, como estratégia para equilibrar as finanças de outros ramos do seguro social, estreitou-se a base de cálculo para as contribuições de aposentados, desempregados e beneficiários da assistência social pagas respectivamente pela previdência social, seguro-desemprego e municipalidades ao GKV, produzindo, $\mathrm{em}$ conseqüência, redução das receitas das Caixas. ${ }^{206}$

Ao mesmo tempo, as Caixas foram obrigadas a aumentar as contribuições de seus segurados para a previdência c para o seguro-descmprego durante a vigência do auxílio-doença. Estima-se impacto negativo dessas medidas sobre as receitas do Seguro Social de Doença, por volta de 5 bilhões anuais, o equivalente ao déficit do GKV na região ocidental em 1995 (Am Orde, 1996; CSU/FDP, 1996b; Gerlinger \& Schönwälder, 1996).

206 Em 1995, por cxemplo, a base de cálculo das contribuições para a saúde, pagas pelo Ministério do Trabalho para os beneficiários de seguro-desemprego, foi reduzida de $100 \%$ para $80 \%$ do último salário bruto. 


\section{Evolução dos gastos: gastos do GKV como proporção do DNB}

De fato é difícil apontar uma contínua explosão de gastos se analisada a cvolução das despesas do sistema de Seguro Social de Docnça GKV em relação ao PNB. Após o período de intensa cxpansão - de ampliação de serviços, clientela c gastos - entre 1970 e 1975, os gastos do GKV, como proporção do produto nacional bruto, permaneceram quase constantes, apresentando oscilaçōes de apenas meio ponto percentual cm sua participação no PNB. A média da participação dos gastos do GKV no PIB, entre 1976 e 1985, foi de $5,8 \%$. Entre 1986 c 1995, a média desta participação ficou em 5,9\% (Stcffen, 1996a).

Não é possível, portanto, caracterizar a cvolução dos gastos cm saúde na Alcmanhla - scjam estes totais ou do scguro social - como cm contínua cxplosāo (Kühn, 1995b; Deppe, 1996a; Steffen, 1996a; Gerlinger \& Schönwälder, 1996; Stcgmü̈ller, 1996a). O que se observa é a estabilidade da participação dos gastos do GKV no PNB. Mesmo para os gastos totais na região ocidental, a participaşão no PNB é quase estável, tendo aumentado apenas um ponto percentual em vinte anos (gráfico 5).

Gráfico 5 - Evolução das taxas de contribuição e das participaçōes dos gastos totais em saúde e do GKV no PNB. Alemanha, Região Ocidental - 1970-1994

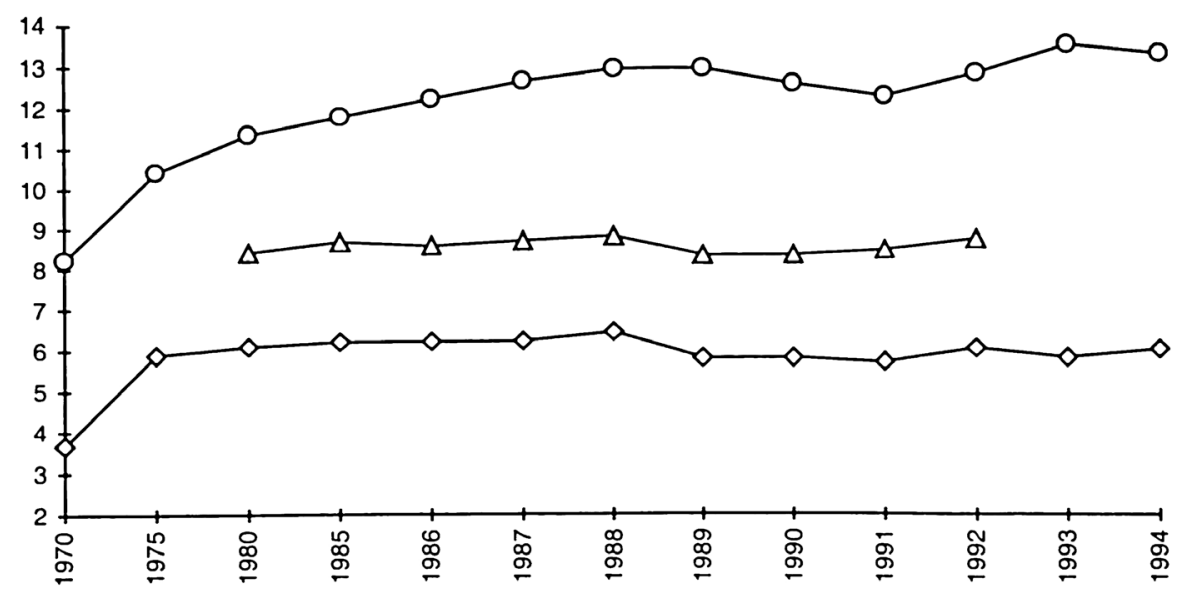

$\multimap$ GKV \% PIB $\neg-$ Gastos totais em saúde como \% PIB $\multimap-$ Taxas de contribuição

Fontc: Kühn, 1995b; BMG, 1996; Stcgmüller, 1996a; Bundesregicrung - Presse und Informationsamt, 1997a. 
Em síntese, pode-se afirmar que as taxas de contribuição permaneceriam estáveis se a participação da renda do trabalho assalariado e o nível de ocupação durante o período tivessem sido sustentados no mesmo patamar, dado ter permanecido quase constante a participação dos gastos do GKV no PNB desde 19751980. O problema principal, assim, é menos de descontrole de gastos, interno aos sistemas de seguro e de atenção à saúde, e mais de erosão das receitas.

Elucidar o problema da erosão das receitas não implica afirmar a inexistência de problemas na evolução dos gastos. A evolução dos gastos manteve dinâmica própria induzida pela oferta e ocorreu de forma independente e paralela ao estreitamento da base de financiamento do Seguro Social de Doença, decorrente da tendência à crise econômica evidenciada desde a metade dos anos 70 , que marcou o fim do período de prosperidade do pós-guerra, o chamado 'milagre alemão’, com suas elevadas taxas de crescimento, e levou a perdas reais dos trabalhadores assalariados e ao aumento do desemprego.

Problemas na organização da atenção e a falta de maior controle sobre os prestadores, assim como a não implementação de medidas anteriormente acordadas, são também apontados como responsáveis pelos déficits atuais do GKV. Entre os problemas organizacionais são referidos a falta de articulação entre a atenção ambulatorial e hospitalar, as formas de remuneração dos prestadores, em especial, da atividade ambulatorial por meio de unidades de serviço, o reduzido controle sobre o mercado farmacêutico, entre outros.

Em outra perspectiva, o crescimento dos gastos em saúde não seria um problema. A expansão dos serviços sociais pessoais é apontada como parte da solução para o problema da produtividade crescente, mediante a qual o conjunto dos bens materiais é produzido por parcela menor da força de trabalho, resultando em desemprego. A expansão de gastos sociais, considerando-se que estes podem ser realizados de forma eficiente, seria um possível resultado positivo do aumento da produtividade do trabalho (Kühn, 1996). Para outros autores, ainda, se o problema é a base da arrecadação, a solução estaria em mudança radical: a modificação do modelo de seguro social para um sistema universal financiado com recursos fiscais (Offe, 1990; Mayntz \& Scharpf, 1995). ${ }^{207}$

\footnotetext{
207 Nesta perspectiva, o modelo universalista adotado no Brasil não seria extemporâneo, mas sim avançado. Autores que discutem mudanças estruturais na esfera do trabalho, não apenas a redução de postos de trabalho, mas também maior rotatividade, períodos mais freqüentes de desemprego etc. indicam como melhor alternativa para a proteção os sistemas universais com base em contribuições fiscais. Não obstante, também para defensores da redução dos custos sociais do trabalho, um sistema universal de base fiscal é apontado para reduzir custos sociais do trabalho e melhorar a posição de competitividade do país (Biedenkopf, 1993).
} 


\section{Crescimento dos Gastos em Saúde: mitos, retórica e consensos}

O principal objetivo das reformas recentes dos sistemas de proteção e atenção à saúde nos países centrais na última década tem sido a contenção de gastos. Mesmo que em diversos países, como é o caso da Alemanha, não se possa falar em 'explosão de custos', csta tem sido a metáfora empregada para a necessidade de reformas 'neo-eficientistas'.

A expansão dos gastos em saúde não é uma particularidade do sistema de saúde alemão nem fenômeno recente. É observada na grande maioria das cconomias desenvolvidas - em particular, desde os anos 50 -, concomitante à extensão das formas de proteção à saúde após a universalização dos direitos sociais de cidadania.

A elevação progressiva dos gastos com assistência à saúde no pós-guerra é inquestionável. Contudo, esse fato tem sido encarado como problema apenas em tempos rccentes. Os gastos em saúde tornaram-se uma preocupação quando, a partir da metade dos anos 70, o cresciménto econômico alterou-se, ficando mais lento. Como alta proporção desses gastos eram públicos e foi mantido o nível de impostos, o baixo crescimento econômico reduziu as receitas governamentais, gerando pressões por contenção (Aaron, 1996; Almeida, 1995 e 1996).

A novidade atual está na sua consideraçāo como problema por amplos setores. $\mathrm{O}$ aumento gradual dos gastos em saúde tem sido ponderado no mundo contemporâneo como problema tanto por governos conservadores como por socialdemocratas. A questão tornou-se objeto privilegiado de estudo para economistas da saúde, tendo sido publicada vasta literatura que enfoca seus difcrentes aspectos. Entretanto, não há consenso acerca das razōes da expansão de custos e gastos e, principalmente, a respeito da importância relativa de cada um dos fatores envolvidos no complexo processo de determinação dos mesmos. Dependendo da influência atribuída aos fatores arrolados, soluções diversas são apontadas. Os diversos autores enfatizam distintos aspectos, tornando-se difícil separar o que é ideologia - o estrito interesse de contenção - e análise distanciada, pois o campo dos recursos públicos é prenhe de disputas.

No contexto de globalização da economia e com a intensificaçăo da competição internacional, as pressōes para reduçāo de gastos em saúde intensificaram-se. O crescimento da parcela dos gastos públicos tem merecido maiores cuidados do que o do conjunto dos gastos em saúde. O aumento dos gastos totais não teria maior importância - a menos que pressionem as despesas governamentais -, uma vez que, sejam altos ou baixos, representariam apcnas o prestígio de determinado setor (o de saúde) no conjunto da economia, não exercen- 
do influência na competitividade internacional. De fato, para os gastos públicos, não há qualquer relação entre o seu patamar c a posição de um país na competição internacional.

Os gastos em saúde são avaliados como tendo peso quanto à competitividade apenas quando os gastos públicos afctam o balanço dos orçamentos governamentais - o equilíbrio fiscal - ou no caso de o volume de gastos privados alterar os níveis de poupança e investimentos privados (Aaron, 1996).

No caso da Alemanha, os gastos públicos são, na maior parte, financiados por contribuições sociais vinculadas aos salários, o que interfere nos custos do trabalho. Desse modo, os cmpresários rcivindicam a redução dos custos sociais do trabalho sob a alegação de que as taxas de contribuição social devem ser cstabilizadas ou reduzidas para que os custos do trabalho sejam contidos, de modo que a Alemanha melhore a sua já excelente posição na competição intcrnacional. ${ }^{2018}$

Carcce de melhor fundamentação, todavia, a argumentação de empresários de que os custos do trabalho foram acrescidos por conta da elevação das taxas de contribuição, ou que são obrigados a pagar seguro-saúde para seus empregados, o que não ocorreria $\mathrm{cm}$ outros paíscs ${ }^{209}$ e levaria à piora de sua posição na competitividade internacional. Na Alemanha, a cota de participação dos rendimentos do trabalho no PNB tem diminuído. Além disso, a comparação internacional dos gastos em saúde mostra que não é possível estabelecer relação ou comprovar a tese, muito difundida pelos conservadores, de que haveria conexão cntre nível de gastos cm saúde e posição de um país na competição internacional. Os países com maior compctitividade - o que pode ser expresso, grosso modo, pelo nívcl de exportações - apresentam, em geral, gastos mais altos e os de pior posição, menores gastos em saúde como proporçāo do PNB, exceto o Japão. ${ }^{210}$

A base ampliada de defcsa da inevitabilidade de contenção é possível não apenas por imposições de políticas de controle dos déficits públicos, com as quais diversos governos têm se defrontado, mas também pela forma de exposição do problema como exigência intrínseca, decorrente da natureza específica dos gastos

\footnotetext{
208 A Alemanha ocupa o segundo lugar no volume linanceiro de exportaçōes; situa-se após os EUA e antes do Japão. É responsável por cerca de 10\% das exportações mundiais. Mais da metade destas têm como destino os países da Uniāo Furopéia. O mesmo ocorre com as imporlaçōes alemãs: $55 \%$ têm como origem os países curopeus.

209 Como por cxemplo, nos países asiáticos. Contudo, para a Coréia do Sul é interessante observar que ampliou a cobertura da proteção social à saúde, em 1989 , para $100 \%$ da população, segundo dados da OFCD. Mantém, porém, um dos níveis mais altos de participação direta dos usuários: cerca de $40 \%$ (OECD Windows, 1997).

210 Os 20 países com maior volume monetário de exportaçōes em ordem decrescente em 1996 exam: EUA, Alemanha, Japão, França, Grā-Bretanha, Itália, Canadá, Holanda, Hong Kong, Benelux, China, Coréia do Sul, Singapura, Taiwan, Espanha, México, Suécia, Suíça, Malásia, Rússia (Bundestegicrung; 1997c).
} 
em saúde. Os defensores mais aguerridos da contenção buscam alicerçar-se em raciocínios fundamentados em aspectos econômicos e, por vezes, até biológicos, apresentados como neutros para a sustentaçāo de políticas nco-eficientistas.

Os argumentos aparentemente mais imparciais fundam-se em análises custo-bencfício. ${ }^{211}$ Em termos economicistas, a contençāo de gastos em saúde seria essencial. O raciocínio é o seguinte: uma vez que a maioria dos gastos em saúde é despendida em assistência médica e que, atingido determinado nível, o aumento dos gastos não traz maiores incrementos à expectativa e/ou à qualidade de vida da população, tornar-se-iam necessárias medidas racionalizadoras (Médici, 1994a). ${ }^{212}$ Motivo menos nobre seria o de os preços em saúde tenderem a subir mais do que os índices de preços.

Semelhantes raciocínios não são desprovidos de fundamento. Constituem rcfcrências necessárias à formulação de políticas de saúde intcrsetoriais que tenham por objetivo melhorar a saúde das populaçōes. Considerando-sc o processo saúde e doença como socialmente determinado, a atenção à saúde surge como um dos fatores em segunda instância que podem influenciar no adoecer e morrer das populações. É sempre difícil avaliar o impacto das açōes de saúde no estado de saúde, isto é, nos resultados de saúde, uma vez que se reconhece o importante impacto de mudanças nas condições de vida, de ações de redistribuição de renda e mesmo dc ações ambientais, nutricionais e educacionais no estado de saúde das populações (McKeown, 1976; Wilkinson, 1997, Pearce, 1997).

Mesmo assim, verifica-se correlaçāo positiva entre gasıos em saúde e esperança de vida. $\mathrm{O}$ que não poderia ser de outra maneira, em virtude de haver correlação positiva cntre renda per capita e expectativa de vida, afora o fato de os países mais ricos tenderem a gastar mais em saúde. Contudo, tal relação não ć direta. No caso de gastos muito baixos, nāo pode ser evidenciada; apenas quando os gastos atingem determinado patamar, a correlação positiva aparece. No outro limite, o de gastos mais altos, a correlação também desaparece. Todavia, estes limites não são consensuais.

A perda desta correlação no limitc superior pode ter explicação óbvia. Existe um limite biológico para a extensão da vida humana, mesmo que não se possa precisar qual. ${ }^{213}$ Atingida certa idade avançada, maiorcs gastos com assis-

211 Este é o caso da discussão sobre o estabelecimento de prioridades e a definiçío de cestas mínimas. Como, por cxemplo, as recomendaçōes do Banco Mundial (1993) para países pobres: os gastos devcriam ser apenas com ações preventivas, sem qualquer dispêndio com açōes que aliviem o sofrimento das pessoas, pois estes não resultariam em reduçāo dos anos de vida perdidos ou vividos com incapacidade (tomados como medida do benclício).

212 Esse argumento, contudo, não pode servir de base para a formulaçāo de qualquer política de saúde no Brasil, pois em qualquer aspecto que se considere em termos intemacionais - seja como proporgão do PNB, seja per capita - o volume de gastos em saúde no Brasil ć baixo.

213 Alguns autores trabalham com 85 anos como a taxa de expcctativa de vida a que se pode chegar. Mais recentementc aponta-se a idade de 90 . Taxas mais elevadas só scriam possíveis no caso de ruptura das fronteiras do conhecimento atual (Olshansky, Carnes \& Cassel, 1993). 
tência médica nāo seriam capazes de estender ainda mais a vida. Poderiam, sem dúvida, aumentar o nível de conforto ou a qualidade de vida dos indivíduos.

O problema deste argumento é sua utilização apenas como base para a cxigência de contenção de gastos em saúde e não de novas concepçōes para as políticas de saúde. Embora exista limite biológico para o prolongamento da vida (difícil de ser determinado) há cvidências de que a erupçāo das doenças crônicas pode ser retardada para idades mais avançadas (Fries, 1984; Kühn, 1995c) e que a qualidade de vida na velhice - assim como em qualquer idade - apresenta distinçōes de classe social (House, Kessler \& Herzog, 1990). ${ }^{21 \cdot 4}$

Quando as restrições crônicas são analisadas de forma diferenciada conforme o status sociocconômico, conhece-se que a duração e a qualidade de vida dos scres humanos não está determinada por um destino biológico ou demográfico. A tese da piora da qualidade de vida nos anos de vida prolongados às custas do progresso médico é válida apenas para as populações pertencentes aos extratos sociocconômicos inferiores. Esse conhecimento implicaria direcionar as políticas de saúde no sentido da promoção da saúde de forma coletiva e do alcance de maior eqüidade em resultados de saúde.

A formulação de políticas intersctoriais fundadas no conceito ampliado de saúde - como aquele incorporado à constituiçāo brasileira - ou mesmo a introdução de ações preventivas de escopo menos abrangente não implicam, de forma imediata, a redução de gastos e, por isso, são preteridos. A operacionalização do enfoque ampliado pressuporia até nova abordagem para gastos em saúde, mas não está dado previamente se maiores ou menores.

Na discussāo internacional quanto aos gastos c custos crescentes da atenção médica, diversos fatores são arrolados. A expansão dos gastos é ponderada, com maior freqüência, como sendo motivada: pela extensão de cobertura da proteção à saúde c ampliação da oferta de serviços médico-sanitários; pelo envelhecimento populacional e transformação na estrutura de morbi-mortalidade; pelo desenvolvimento da tecnologia médica $\mathrm{e}$ intensificação dos cuidados; pela variabilidade das condutas médicas; e, enfim, pela dominância dos prestadores.

\section{Extensão de cobertura}

Na maioria dos países da OECD, a atençāo à saúde, assim como a cducação, foi e é julgada um direito de todos os cidadãos. Entende-se que a garantia do direito à saúde não pode ser deixada ao mercado privado, no qual cada um compra

214 Esses autores encontraram por exemplo que as pessoas entre 35 e 40 anos do estrato econônico mais baixo apresentaram um nível de doenças crônicas $\mathrm{c}$ restrições similar àquele da população de 75 anos e mais do estrato socioeconômico mais elevado. O que demonstra que nos grupos sociais de maior renda já ocorreu uma compressão da morbidade para idades mais avançadas. 
conforme sua disponibilidade de recursos financeiros. A universalização do direito à saúde decorreu de processos históricos e sociais, nos quais a mobilização dos trabalhadores organizados pela melhoria das condiçōes de vida foi de fundamental importância. ${ }^{215} \mathrm{O}$ propósito principal da extensão dos seguros sociais de saúde compulsórios ou de sistemas nacionais de saúde com a universalização do direito à saúde foi prevenir a situação em que pessoas permaneçam sem cuidados em decorrência da falta de condições financeiras para pagá-los quando da necessidade de sua utilização. ${ }^{216}$

Com isso, foram criados sistemas sociais de proteçāo, na forma de seguros sociais compulsórios ou de sistemas públicos nacionais de saúde, que estenderam, pouco a pouco, a cobertura ao conjunto da população, universalizando a proteção. Entre os membros tradicionais da OECD, quase todos os países, com exceção dos EUA e Suíça, ${ }^{217}$ experimentaram um processo de universalização da cobertura de esquemas públicos de proteção à saúde. Em sua maioria, essa proteção foi universalizada antes dos anos 70 (Abel-Smith, 1996).

A expansão de gastos segue-se à extensāo da cobertura como conseqüência direta da facilitaçăo do acesso e do aumento do número de possíveis consumidores. $\mathrm{O}$ asseguramento obrigatório e a cobertura pública universal, contudo, nāo produzem maiores gastos que o consumo por meio de seguros privados. A curto prazo, o asseguramento público tende a aumentar gastos, mas estes sistemas em geral são mais vantajosos, a longo prazo, em termos financeiros. Por facilitar o controle, os gastos dos seguros compulsórios vêm a ser menores do que os produzidos pelo asseguramento voluntário privado. O Reino Unido foi um dos países em que a cobertura universal foi garantida mais cedo pela via legal. Nos anos 50 , argumentava-se que a universalização levaria a consumo descontrolado. Mas já no início dos anos 60 observou-se que a participação dos gastos totais em saúde no PNB tinha sido reduzida. Essa proporção tem-se mantido, até o momento, em níveis mais baixos, quando comparada a outros países no mesmo patamar de industrialização (Lobato, 1997). O exemplo dos EUA, mostra que a soluçāo via mercado implica prêmios e gastos mais altos que os do asseguramento compulsó-

215 A universalização do direito à saúde é parte do processo de construção dos welfare states. Para uma boa discussão e compreensão sobre a origem e expansão dos welfare states, ver Fleury, 1996.

216 A exigência de asseguramento decorre também de característica essencial do cuidado de saúde: é raro que sua necessidade possa ser prognosticada. Atualmente, os cuidados de saúde são onerosos demais para que possam ser pagos no ato com os próprios recursos do usuário e muitas famílias não têm condições de custear prêmios de seguros privados. Os seguros privados, cujos prêmios sāo definidos com base no risco de adoecer, oneram de maneira excessiva aqueles que mais necessitam de proteção - idosos e doentes crônicos, sem falar nos menos favorecidos economicamente.

217 A Suíça vem caminhando nessa direção e, mesmo nos EUA, têm sido formuladas propostas governamentais para garantir a universalização. A Turquia tem planos para alcançá-la antes do próximo milênio. 
rio regulado. Colocar o asseguramento da saúde no domínio dos gastos públicos tem possibilitado uma expansão mais moderada dos gastos.

\section{Envelhecimento populacional}

Embora o envelhecimento populacional seja tradicionalmente apontado e evocado pela sua visibilidade como o principal argumento da necessidade de controle de gastos, diversos autores têm demonstrado que este fator não influencia de forma determinante a dinâmica atual de evoluçāo dos gastos em saúde (Scitovsky, 1988; Fuchs apud Abel-Smith, 1996; Schwartz \& Busse, 1994; Gerdtham, 1993). ${ }^{218}$

Nas justificativas de medidas de contenção, apresentadas por governos conservadores, empresários e liberais, afirma-se ser imperativo o controle de gastos, pois a evolução demográfica, ao produzir uma população cada vez mais idosa e existindo proporçāo cada vez maior de velhos, levaria à contínua expansão dos gastos em saúde, tornando impossível financiá-los de maneira solidária. $\mathrm{O}$ desenvolvimento demográfico seria o componente que detonaria a explosão de gastos em saúde.

Nos países industrializados, o envelhecimento demográfico é resultado de longo processo, de mais de um século, de reduçāo gradual da mortalidade e de queda da natalidade. A redução da mortalidade por si só não faz aumentar a proporção de velhos em uma população, mas produz ganhos de vidas humanas em todas as idades, em particular, entre os mais jovens, aumentando a proporção destes em um primeiro momento. $\mathrm{O}$ que pesa de modo decisivo para o envelhecimento da população é a queda da fecundidade. A mudança da estrutura etária populacional com a acumulação progressiva de proporção de pessoas em idade mais avançada somente sucede ao declínio da mortalidade se houver diminuição concomitante no número de nascimentos (Berquó, 1980).

$\mathrm{O}$ argumento relativo ao envelhecimento populacional não é de todo desprovido de fundamento, mas não tem o mesmo sentido para o seguro social de doença e para a previdência social, na qual a relação contribuintes/beneficiários declinaria pouco a pouco, fazendo com que um número decrescente de jovens fosse obrigado a financiar proteção a um número de velhos progressivamente maior. $\mathrm{O}$ envelhecimento populacional traz conseqüências para as condições de saúde e bem-estar em razão de o risco de adoecimento aumentar com a idade, com repercussōes nos indicadores de mortalidade. Os estudos a respeito da transição demográfica demonstram o rápido crescimento da proporção de mortes por doenças crônico-degenerativas - em particular, as cardiovasculares e os tumores - paralelamente ao claro declínio das doenças infecciosas e parasitárias.

218 Em especial nos países que completaram a transiçăo demográfica. 
Isso nāo significa, porém, que a mortalidade por essas doenças venha aumentando de modo gradual. Ocorre que as taxas de mortalidade por doenças crônico-degenerativas é maior em faixas etárias mais elevadas (Possas, 1993). Considerada a proporção de mortes, observa-se aumento da importância das doenças crônico-dcgenerativas em virtude da redução das doenças infecciosas e parasitárias. Contudo, quando se relaciona a mortalidade com a populaçāo e se avalia o risco de morrer por diferentes tipos de causas, verifica-se ter ocorrido redução para o maior número de causas, não apenas para as infecciosas $\mathrm{c}$ parasitárias.

Estudos relativos à mortalidade adulta nas economias desenvolvidas têm demonstrado que taxas específicas por idade para diversas doenças crônicodegenerativas estão declinando. ${ }^{219}$ Tais pesquisas mostram que, quando a mortalidade cai, as taxas específicas também declinam nos grupos etários até 60 anos tanto para as doenças infecciosas como para as crônico-degenerativas (Murray, Yang e Qiao apud Possas, 1993). ${ }^{220}$

Também se leva em conta o fato, há muito reconhecido, de as pessoas necessitarem mais cuidados de saúde ao cnvelhecer. Em diversos países tem sido demonstrado que os gastos com atenção à saúde são três vezes maiores para homens cntre 65 e 74 anos do que para aqucles entrc 15 e 44 anos. Além disso, idosos com 75 anos ou mais gastam o dobro do que os membros do grupo entre 65 e 74 anos (Sandier apud Abel-Smith, 1996). Na Alemanha, os gastos per capita com pessoas maiores de 65 anos constituem o dobro daqueles com pessoas entre 45 e 65 anos (Schwartz \& Busse, 1994).

Maiores gastos em saúde para as idades mais avançadas, todavia, não estāo diretamente relacionados ao envelhccimento populacional, mas à intensificação dos cuidados nos últimos anos de vida. Cerca de um quinto dos gastos em saúde é efetuado no último ano de vida da pcssoa, independentc de sua idade. Estudos mostram que o aumento dos custos concernentes aos cuidados de saúde relacionados à idade pode ser cxplicado, quase que na íntegra, pelos custos dos cuidados de saúde prestados às pessoas que morrem no espaço de um ano c que essas despesas estāo concentradas no último ou nos dois últimos meses de suas vidas (Fuchs apud Abcl-Smith, 1996). Assim, não se pode afirmar que quanto mais velha a população maiores serão os gastos em saúdc. Os gastos em saúde concentram-se no último ano de vida, mas não são diretamente relacionados à idade.

219) Possas (1993) contudo adverte que não se deve tirar conclusões apressadas destes cstudos, aplicando-os aos países em desenvolvimento com o intuito de defender que não é preciso preocupar-se com o aumento de doenças crônico-degenerativas, como fazem os organismos internacionais que propōem cestas mínimas.

220 Nas economias desenvolvidas, por exemplo, as taxas de mortalidade para algumas docnças cardiovasculares têm inclusive declinado e seu desfecho advém $\mathrm{cm}$ idades mais avançadas. As mortes por doenças cardiovasculares no Brasil ocorrem em idade mais precoce, além de as taxas de mortalidade serem mais clevadas do que nos EUA, por exemplo (Chor et al., 1995). 
Além disso, ao contrário do que se acredita, os gastos com idosos de 80 anos ou mais podem ser mais baixos do que aqueles com pessoas menos velhas (65 a 79 anos). Uma pesquisa feita nos EUA mostrou que os gastos com pessoas que morrem com 80 anos ou mais representam apenas $80 \%$ dos gastos efetuados com pessoas que morrem entre 65 e 79 anos. Em idades muito avançadas, o gasto não apenas é menor, como a composição do gasto também é diferente, pois sc concentra em cuidados domiciliares - médicos e cnfermagem - (Scitovsky, 1988). Os resultados desse estudo mostram que o adoccimento grave de pessoas de idade não muito avançada leva a emprego mais intensivo de tecnologias onerosas do que para as de idade avançada, além de sugerirem que a elevação da expectativa de vida para além dos 80 anos poderia resultar em diminuição dos gastos em saúde, ou pelo menos que os gastos em idades avançadas não aumentam progressivamente com a idade. ${ }^{221}$

Os efeitos das mudanças demográficas nos gastos com cuidados de saúde foram freqüentemente superestimados. Pesquisas mais recentes feitas para os países de industrialização avançada têm demonstrado a pequena participação do fator envelhecimento na evolução dos gastos em saúde. Em 20 anos, este foi responsável por apenas $8 \%$ do crescimento dos gastos do Serviço Nacional de Saúde Britânico. Estimativas para Holanda e França apontam ser o envelhecimento populacional responsável por apenas $0,3 \%$ de aumento dos gastos de saúdc por ano (Abel-Smith, 1996). Na Suécia, a evolução demográfica foi responsável por menos de um quarto do aumento dos gastos com saúde entre $1970 \mathrm{e}$ 1985. Contabilizado por ano, o aumento de gastos explicados pelo fator demografia foi de apenas $0,8 \% \mathrm{e}$, para o período de 1985 a 2005 , estima-se redução no impacto das mudanças demográficas para $0,3 \%$ ao ano (Gerdtham, 1993). Na Alemanha, demonstrou-se que as mudanças demográficas condicionaram aumento de $0,2 \%$ na utilização e de $0,5 \%$ nos gastos em saúde ao ano, durante os anos 80 (Schwartz \& Busse, 1994).

O envelhecimento da população alemã influi indiretamente nos gastos em saúde devido à 'intensificação dos cuidados' em saúde para grupos populacionais idosos. Os gastos em saúde correspondentes às pessoas de idade mais avançada aumentaram nos últimos 20 anos com maior rapideż do que para os mais jovens, o que pode ser evidenciado por meio da comparação entre os gastos com saúde dos aposentados e dos outros integrantes do Seguro Social de Doença. Em 1970, a parcela de gastos dos aposentados no conjunto dos

221 Afirmaçōes como esta são evidentcmente muito precipitadas. O estudo teria de ser replicado e não é possível prever quais tecnologias estarão disponíveis no futuro. Além disso, no caso do Brasil, em certos hospitais, a ganância financeira associada à falta de ética leva à produção de procedimentos invasivos, mesmo para pacientes terminais de mais de 90 anos de idade, como por exemplo, entubamento e a internação em UTI. 
gastos cra de $26,7 \%$, apenas levemente mais alta do que a cota de participação de segurados aposentados no GKV (26,1\%). Em 1992, a cota de aposentados $(27,6 \%)$ permanecia similar, porém, sua utilização de serviços de saúde produzia $41,7 \%$ dos gastos. ${ }^{222}$

A pouca influência direta, atual e futura do envelhecimento populacional nos gastos em saúde na Alcmanha é bem ilustrada quando se observa a evolução demográfica nas últimas décadas. Como se pode verificar na tabela abaixo, a proporção de pessoas com 65 anos ou mais mantém-se estável, em torno de 15\%, desde $1975 .{ }^{223}$ Em vista desta estabilidade, não é de sc esperar impacto cxplosivo do envelhecimento populacional nos gastos em saúde.

Tabela 20 - Proporção de pessoas com 65 anos ou mais.* Países selecionados - 1960, 1976 e 1990

\begin{tabular}{lrrr}
\hline Paíscs & 1960 & 1976 & 1990 \\
\hline Alcmanha & 10,2 & 14,7 & 15,3 \\
Áustria & 12,2 & 15,1 & 15,1 \\
Canadá & 7,6 & 8,7 & 11,5 \\
EUA & 9,2 & 10,7 & 12,6 \\
França & 11,6 & 13,5 & 14,0 \\
Itália & 9,2 & 12,5 & 15,3 \\
Japão & 5,7 & 8,1 & 12,0 \\
Rcino Unido & 11,7 & 14,2 & 15,7 \\
Sućcia & 11,8 & 15,4 & 17,8 \\
Suíça & 10,7 & 13,4 & 15,0 \\
\hline
\end{tabular}

*\% da populaçāo total.

Fontc: OECD, 1993b.

Cálculos referentes à evolução da taxa média de contribuição do GKV prognosticam elevação das mesmas, condicionadas pela evoluçāo demográfica, em apenas 1,3 pontos percentuais entre 1993 e 2005 (Gerlinger \& Schönwälder, 1996). Pode-se afirmar, portanto, que os efeitos da evoluçāo demográfica no aumento dos gastos em saúde, ainda que relevantes, não são tão importantes quanto parecem em análise mais apressada (ou ideologicamente mais intencionada). Os efeitos do envelhecimento populacional tendem a reduzir conforme se completa o ciclo da

222 Os gastos com os aposentados que mais aumentaram foram os referentes a medicamentos $\mathrm{c}$ internações hospitalares. Em 1992, 54,3\% dos gastos com medicamentos e 52,2\% dos gastos com internaçōes hospitalares corresponderam ao tratamento de aposemtados (SVR, 1994).

223 Entre 1960 e 1975 observou-se aumento importante desta proporção - quase 50\% - mesmo período $\mathrm{cm}$ que ocorreu maior aumento dos gastos $\mathrm{em}$ saúde. 
transição demográfica, previsto, na Alemanha, para 2030. Além disso, a curva de custos com os idosos não sobe linearmente ou exponencialmente de acordo com o alcance de idades mais avançadas. Depois dos 80 anos há redução dos gastos com atenção à saúde, em particular daqueles com cuidados invasivos. ${ }^{224}$ Embora o crescimento da parcela da população de idade avançada possa vir a influenciar de forma expressiva os gastos com cuidados sociais mais amplos, ${ }^{22.5}$ o envelhccimento não será fator importante no crescimento dos gastos com cuidados de saúde. ${ }^{226}$

Discutir com profundidade o fator envelhecimento populacional permite desmascarar a aparente neutralidade de determinados argumentos empregados na defesa de cortes na área social. Sob o termo envelhecimento populacional subentende-se, em geral, a elevação da expectativa de vida, objetivo amplamente descjado. Como é ambicionado e incvitável e aparece como característica biológica, a consideração do envelhecimento populacional como responsável por gastos crescentes leva à 'naturalizaçāo' do problema do incremento dos gastos. Desse modo, confere-se aparente imparcialidade ao argumento de inevitabilidade da contençāo. Esta estaria detcrminada por um 'destino biológico'.

A ênfase no aspecto do envelhecimento populacional tem como conseqüência a conclusão de que não seria possível financiar de modo solidário os gastos $\mathrm{em}$ saúde, pois sua cvolução fugiria ao controle e independeria da ação de prestadores; dos modos de organização da oferta; de determinado desenvolvimento e de incorporaçāo das tecnologias no setor; ou, mesmo, de outras medidas mais ampliadas de promoção da saúde. $\mathrm{O}$ aumento seria incontrolável e o problema insolúvel. Desse modo, a única opção seria cortar, racionar, pois não seria possível gastar tanto para tão poucos resultados. A naturalização leva à inevitabilidade do racionamento. $\mathrm{O}$ que atende a exigências ideológicas neoconservadoras, mas não corresponde nem aos problemas setoriais nem às necessidades reais dos pacicntes. ${ }^{227}$

$221 \mathrm{Na}$ Alemanha, ainda que a proporçăo de pessoas com 65 anos ou mais possa ser considerada estável, nos últimos anos houve aumento da proporção da população em idades mais avançadlas. O grupo de 80 anos ou mais elevou-se de $2,1 \%$, em 1975 , para $3,8 \%$, em 1990 , e o grupo de 75 anos ou mais passou de $4,8 \%$ para $7,2 \%$ da população total no mesmo período (OECD, 1993b). Para dar conta das novas necessidades desse grupo populacional, foi criado novo ramo do scguro social para cuidados de enfermagem de longa duração, como referido no capítulo 1 .

$225 \mathrm{Na}$ Alemanha, a questão do envelhecimento populacional é tema de discussão acirrada principalmente em outras áreas da proteção social, em particular, no que toca às aposentadorias.

226 Além disso, na Alemanha, o impacto das mudanças demográficas sobre os gastos em saúde pode ainda ser menor se for considerado o movimento migratório e a maior taxa de natalidade entre os imigrantes. A maioria das estimativas de projeções de evoluçāo demográfica discutidas de modo ampliado levam en conta um movimento migratório muito baixo. Caso o movimento migratório seja devidamente ponderado, as estimativas indicarão claro rejuvenescimento populacional (Birg apud Schwartz \& Busse, 1994).

227 Para Schwartz \& Busse (1994), a reclamação sobre os gastos crescentes devido ao envelhecimento da população é irônica inversão de valores. No século XIX, a aspiração era que todas as pessoas alcanf̧assem o seu limite biológico. Agora que cste foi atingido ou está próximo na Alemanha, lastima-se como estado de calamidade ou situação de emcrgência. 
A tese de que se necessita de cuidados em demasia com o avanço da idade é, em especial, atrativa em períodos de restrições financeiras e utilizada por neoconservadores que sempre consideraram os sistemas de welfare muito caros ou prejudiciais ao livre desenvolvimento das forças de mercado. O aumento da expectativa de vida é um triunfo da sociedade, mas para políticos de saúde neoconservadores tornou-se um iminente desastre (Olshansky, Carnes \& Cassel, 1993).

Em síntese, conquanto o tratamento da população com mais de 65 anos de idade incorra em maiores gastos, não se pode responsabilizar o envelhecimento populacional pela elevação dos gastos com saúde na Alemanha. $\mathrm{O}$ acréscimo de gastos ocorreu mais devido à intensificação dos cuidados. Isto é, número maior e/ ou ações mais caras estão sendo dispensadas aos contribuintes aposentados, o que está relacionado tanto a mudanças e emprego da tecnologia médica quanto à forma de prestação de serviços de saúde, fatores analisados a seguir.

\section{Desenvolvimento da tecnologia médica}

Assim como o envelhecimento populacional, o emprego de novas tecnologias médicas tem sido avaliado como das principais causas detonadoras $\mathrm{da}$ explosão de gastos em saúde. A expansão tecnológica é ponderada como fator principal para o constante aumento de gastos em saúde, porque a introdução de novas tecnologias produz freqüentemente o aumento de gastos mais do que a sua redução. Costuma-se equiparar as novas e mais caras tecnologias ao progresso médico - apesar de representarem apenas uma faceta deste - e se conclui que, em breve, este se tornará inacessível, não podendo mais fazer parte de esquemas de asseguramento solidário.

Análises mais apuradas mostram, porém, que nem o progresso médico nem a introdução de novas tecnologias leva de forma inexorável ao aumento de gastos. Para Schwartz \& Busse (1994), nąo é tanto o emprego de novas tecnologias que forçosamente provoca a elevação de gastos, mas a forma como estas são introduzidas. ${ }^{228}$

Uma tecnologia pode ser onerosa em decorrência dos altos custos iniciais do equipamento, da exigência de pessoal especializado para empregá-la, do longo processo de pesquisa ou porque, uma vez introduzida, é utilizada de forma inadequada.

As mudanças da tecnologia médica que têm contribuído para a intensificação dos cuidados, associada à complexidade dos casos tratados, têm sido descritas como os principais fatores do aumento dos custos hospitalares. Contudo, estes aumentos não podem ser atribuídos aos avanços do progresso técnico setorial em

228 Com isso, os autores contra-argumentam a proposição de que o progresso médico se tornará impagável. 
si, mas sim a dimensōes do desenvolvimento tecnológico, aos objetivos pelos quais é impulsionado e à forma específica de încorporação das tecnologias do setor saúde. Há evidências também de que não é tanto a introdução dos mais recentes e onerosos avanços tecnológicos que encarecem os cuidados de saúde, gerando a necessidade de aumento dos orçamentos destinados à saúde, mas sim as mudanças incrementais da tecnologia médica.

Um estudo americano a respeito de custos hospitalares mostrou que um terço da intensificação do cuidado foi ocasionada por novas tecnologias e dois terços por pequenas melhorias tecnológicas e mudanças nos padrões de prática médica: maior número ou maior complexidade de ações empregadas em determinada condição patológica (Ashby \& Craig apud Abel-Smith, 1996).

Parte do problema é que novas e caras tecnologias podem ser empregadas de modo que não produzam melhoria de resultado das ações de saúde. Tecnologias mais onerosas podem substituir outras mais antigas, ou ser apenas agregadas sem substituir as usadas antes e os resultados de sua utilização serem os mesmos do emprego da anterior. Novos métodos diagnósticos podem também ser utilizados sem a introdução de abordagens terapêuticas adequadas ou sem influenciar a melhoria do processo terapêutico.

Deste modo, um dos principais problemas com a introdução de novas tecnologias na área da saúde é que podem ser adotadas sem que repercutam em resultados positivos para a saúde dos pacientes, gerando até impacto negativo na eficiência e efetividade da atenção, pois grande parte é difundida mesmo que seu emprego não tenha sido avaliado de modo rigoroso quanto à eficácia e qualidade. A avaliação de tecnologias é prática pouco difundida e, em geral, restrita aos medicamentos. A maioria é introduzida antes de avaliação crítica e das recomendações de comissōes de especialistas ou de sociedades de especialistas.

Muitas tecnologias hoje utilizadas nunca foram avaliadas. ${ }^{229}$ Não é raro o abandono ou a restrição do emprego de tecnologias após longos períodos de uso por ter sido comprovada sua inefetividade ou a possibilidade de produção de graves danos (Abel-Smith, 1996). ${ }^{230}$ Quando são avaliadas, o processo é tão demorado que são implementadas antes de as recomendaçōes terem sido elaboradas. Além disso, essas recomendações costumam derivar de estudos produzidos sob enco-

229 Na União Européia, são requeridas hoje evidências de efetividade apenas para medicamentos. A responsabilidade para estabelecê-las é do produtor e as indicações para o uso devem ser aprovadas pelas autoridades competentes. Nos EUA, a Food and Drugs Administration (FDA) tem avaliado equipamentos e alguns procedimentos.

230 Radiografar fetos foi prática difundida nos anos 30, abandonada depois que se demonstrou que poderia causar leucemia. A amnioncentese foi amplamente utilizada até que se descobriu que poderia causar danos ao feto e a sua utilização foi restringida. Mastectomias totais foram amplamente utilizadas até ser reconhecido que cirurgias localizadas produzem os mesmos resultados. 
menda dos produtores de equipamentos, por médicos e instituições científicas cooperantes. Em virtude de estarem articulados aos interesses dos produtores, o objetivo desses estudos é mais comprovar a utilidade do que avaliar a qualidade $\mathrm{e}$ elaborar recomendações de emprego. Assim, é comum que a difusão de novas tecnologias decorra não de avaliação crítica, mas de clima favorável da opinião médica e pública de que determinada tecnologia ou procedimento responde a necessidades médicas (Schwartz \& Busse, 1994).

Outra razão para que a avaliação de tecnologias seja tão pouco difundida está na dificuldade de estabelecer seu uso apropriado e eficiente. As metodologias são caras e complexas, envolvendo aspectos éticos muitas vezes cruciais. Afora isso, nāo somente os produtores de equipamentos, mas também os prestadores de serviços têm interesse no emprego não padronizado de tecnologias. Nesse caso, equipamentos capital-intensivos onerosos - cuja amortizaçāo apenas é possível com a produção de ações em grande volume - são usados por estarem disponíveis e nāo porque seu uso resultará em melhor qualidade da atençāo.

A necessidade de controle da utilização de tecnologias não decorre só de preocupações com os gastos, mas, principalmente, da qualidade da atenção prestada. Para a decisão de implementação de nova tecnologia em saúde não basta saber se o método é seguro e se afere com acuidade ou realiza aquilo a que se propõe. A questão vital é em que medida o novo procedimento contribui para a melhoria dos resultados e para quais pacientes. Muitas das tecnologias médicas podem ser efetivas unicamente quando aplicadas a pacientes em determinadas situações.

Economistas da saúde alertam para o fato de que, em outro ramos industriais, a maioria das inovaçōes tecnológicas leva à racionalização, com redução de custos, o que não ocorreria no setor saúde. Essa ausência de racionalização aconteceria em razão de a demanda em saúde não ser orientada pelos preços: todas as açōes são ofertadas pelos seguros sociais - no caso da Alemanha, pelo GKV -, quase sem participação financeira direta dos pacientes (Meyer apud Schwartz \& Busse, 1994; Burger \& Kasper, 1998). Esta explicação é o continente de determinado tipo de solução: os pacientes devem pagar para que os preços sejam controlados.

$\mathrm{O}$ aumento de gastos que segue a introdução de novas tecnologias não se deve à garantia pública da atençāo nem é peculiaridade do setor saúde. ${ }^{231}$ Segundo Aaron (1996), para entender o processo pelo qual novas tecnologias produzem aumento de gastos, importa não confundir gastos ( $\cos t$ ), cujo significado é o conjunto das despesas, e preços. Em qualquer setor da economia, mudanças

231 A demanda em saúde é inelástica, não acompanha diretamente a variação de preços. Mesmo em raciocínio economicista, a sinalizaçāo via preços não seria mecanismo adequado ao controle da demanda em saúde, em razão das características específicas do bem saúde. 
tecnológicas diminuem preços, mas costumam acarretar acréscimo de gastos. Uma comparação com a indústria de computadores torna claro que a implantação de novas tecnologias tem levado a reduções notáveis dos preços de produtos, quase que mês a mês, todavia, ao mesmo tempo, a difusão do uso dos computadores tem produzido enorme aumento dos gastos nesta área.

No setor saúde, uma nova tecnologia pode, por vezes, diminuir os preços, mas implicar aumento de gastos, uma vez que a disponibilidade de equipamentos e o fato de o procedimento ser menos invasivo, envolvendo menor risco, estimula aumento do volume de procedimentos produzidos. ${ }^{232}$

De mais a mais, uma característica do setor saúde é que a introdução de novas tecnologias não envolve a substituição de mão-de-obra. Não substitui trabalho (recursos humanos) por capital (equipamentos). Os métodos diagnósticos e terapêuticos inovadores somam-se aos já existentes, as novas tecnologias demandam mais pessoal e profissões que possam operar e interpretar os novos meios tecnológicos, o que encarece a atenção. Assim, por não substituir trabalho por capital, a produtividade do setor saúde avança de forma mais lenta do que em outros setores (Médici, 1994a).

Destacam-se ainda os interesses dos produtores - indústrias farmacêuticas, de equipamentos e insumos médicos - na difusão de novas tecnologias. Os produtores, no afã de abrir novos mercados e aumentar o consumo, criam novas exigências em saúde por parte dos consumidores. Entretanto, a utilização de novas tecnologias não é imposta por parte dos pacientes, que as exigiriam estimulados pelo marketing de produtores e prestadores. A maioria dos pacientes (66\%) julga que seu médico deve resolver acerca do emprego de cquipamentos e tecnologias (Schwartz \& Busse, 1994). Para os pacientes, o mais importante, mesmo na Alemanha, continua a ser a qualidade da interação pessoal médico-paciente e não o emprego de equipamentos. Mesmo assim, nas situaçōes em que medidas terapêuticas efetivas existem, os pacientes não desejam renunciar à tecnologia.

Em síntese, um dos fatores mais importantes na elevação de gastos em saúde é o emprego inadequado de tecnologias, ou seja, introdução de tecnologias sem comprovação, utilização não estandardizada e, em geral, scm reflexão suficiente no que diz respeito ao uso individual.

\section{Diversidade de condutas médicas}

Outro problema ligado ao emprego da tecnologia é a falta de claro conhecimento de quais ações devem ser produzidas - quais recursos devem ser empregados para o tratamento de determinado paciente. $O$ processo de trabalho em

232 Uma retirada da vesícula biliar via laparoscópica, reduzindo o tempo de permanência hospitalar, por exemplo. 
saúde é artesanal: 'A medicina é arte e não técnica', diriam uns. 'Não existem doenças, existem doentes', diriam outros e apelariam à autonomia no exercício da profissão contra qualquer protocolo ou norma de conduta obrigatória.

A multiplicidade nos padrões de prática médica é citada como problema que produz ineficiências na atenção à saúde. Em inúmeras situaçōes há variedade de opçōes quanto ao procedimento a ser empregado. Estas, em geral, envolvem delicadas escolhas: entre a intervenção cirúrgica e o manejo medicamentoso ou entre este e a simples observação por certo período. ${ }^{233} \mathrm{~A}$ diversidade de condutas, decorrente da forma de produçāo do conhecimento médico, do tipo de processo e objetos de trabalho, ou melhor, da falta de condutas normatizadas, aliada a formas específicas de remuneração médica, como o pagamento por unidade de serviço, acarreta a inevitável tentação para intervir e produzir ações desnecessárias.

Há desconhecimento quanto a um cuidado de saúde ser efetivo, apropriado e eficiente no uso dos recursos ou não, tornando-se ainda mais difícil estimar os benefícios prospectivos para um paciente individual. Muitos dos serviços oferecidos podem ser desnecessários, incluindo-se aí, afora o emprego excessivo, aqueles inefetivos ou inadequados. Açōes impróprias são aquelas referentes a tratamentos cujos prováveis riscos excedem os prováveis benefícios ou aquelas cujo emprego efetivo diz respeito à condição diferente da apresentada pelo paciente. As estimativas de ações desnecessárias no Canadá variam entre 30\% e 60\% dos gastos em saúde, ao passo que, nos EUA, estima-se que $30 \%$ dos cuidados são inadequados. É provável que estas proporçōes sejam superestimativas, uma vez que os estudo feitos englobam uma parcela das ações em saúde e não levam em conta que, no caso da abolição das açōes desnecessárias, parte delas seria substituída por outras (Abel-Smith, 1996).

Abel-Smith (1996) questiona também se o médico está em condições de conhecer o que é necessário e apropriado. Embora o conhecimento médico seja julgado científico, é muito mais comum que seja presumido ou inferido do que provado. A aceitação de tratamentos quase sempre resultou de relatórios de médicos baseados em suas experiências com pequeno número de casos e não de cuidadosos estudos populacionais aleatórios.

Apenas recentemente têm sido desenvolvidos estudos para definir protocolos de condutas. Estes podem contribuir para diminuir a variabilidade de condutas médicas e o volume de açóes desnecessárias e impróprias daí decorrentes, aumentando a qualidade ao definir quais tratamentos e quais etapas do tratamen-

233 Em certas situaçōes, os pacientes optam pela observaçăo. Em estudo realizado nos EUA, pacientes com severos sintomas relacionados à próstata optaram pela observação quando lhes foi dada a chance de escolha informada (Abel-Smith, 1996). 
to são necessárias e eficientes, tendo por base os seus resultados. ${ }^{234}$ Isso não significa dizer que a medicina poderia operar sem variaçōes com base em especificações precisas. Os casos individuais variam, bem como as condiçōes em que o serviço é prestado, o que, por sua vez, não impede que orientaçōes mais especificadas possam ser aplicadas.

\section{Dominância dos prestadores}

Finalmente, ncm o envelhecimento populacional nem a difusão de tecnologias médicas onerosas explicaria de maneira convincente porque a carga dos custos de saúdc varia de modo tão amplo entre países em níveis similares de desenvolvimento. Importante fator para explicar tais diferenças está na história institucional do asseguramento e da organização da atenção à saúde nos diversos países. Para Abcl-Smith (1996), o elemento mais importante para explicar a 'explosāo de custos em saúde' em análise de perspectiva de longo prazo é produto da interação histórica entre prestadores e consumidores, que resultou na precedência dos primeiros, em especial, como conseqüência do poder político da profissão médica.

As atuais estruturas dos sistemas de saúde e formas de abordagem para o controle de gastos dependem, de modo cxpressivo, da força política relativa aos grupos de prestadores e de como suas relações de poder com os governos evoluíram ao longo do tempo. Ainda que os próprios consumidores tenham originalmente se organizado para prover o próprio asseguramento, os prestadores passaram a ter o domínio desta relação por interferência dos governos. Segundo Abel-Smith, os prestadores de serviços seriam os responsáveis pela escalada de preços. Resumindo o seu argumento: os primeiros seguros-saúde organizados pelos trabalhadores (consumidores) para garantir acesso a cuidados custcáveis preocupavam-se em controlar custos. Isto levou à pressão e competição entre os prestadores. Frente a consumidores organizados, os prestadores articulavam-se para defender seus interesses, dando resposta às pressões competitivas dos seguradores que ameaçavam suas rendas $\mathrm{e}$ práticas. Quando o conflito tornava-se insuportável, os governos intervinham quase sempre a favor dos prestadores, anulando as medidas de controle de custos propostas pelos consumidores. Desse modo, os prestadores teriam passado a decidir quais cuidados seriam necessários.

234 Importa recordar que quando não formulados por consenso entre especialistas, mas apenas para reduzir custos dos planos de saúde privados, os protocolos podem impedir assistência adequada. É o que pode ocorrer no emprego de protocolos como mecanismo para o controle de gastos pelos scguros privados, a exemplo das $I M M O s$ americanas e operadoras de planos de saúde atuantes no Brasil. 
Em termos econômicos, a relevância dos prestadores na determinação dos aumentos contínuos de gastos com saúde é também decorrente de uma das características do bem saúde: a assimetria de informaçōes (a ignorância do consumidor). $\mathrm{O}$ paciente sofre o desconforto, mas desconhece e pouco opina sobre o que deve ser feito. Essa decisão é deixada ao médico. O paciente tem dúvidas sobre o diagnóstico, o tratamento e o prognóstico. $\mathrm{O}$ médico decide o que deve ser consumido, e inúmeras indústrias se desenvolveram para prover o que o médico precisa para os pacientes ou para persuadi-lo de que seus produtos são essenciais (Abel-Smith, 1996).

O diferente desenvolvimento histórico institucional explica, em grande parte, as expressivas diferenças nos gastos per capita e nos gastos totais como proporção do PNB entre os EUA e os principais países europeus. Nos EUA, o asseguramento desenvolveu-se de múltiplas formas, sendo quase exclusivamente privado e composto, em boa parte, por seguros organizados pelos próprios prestadores de serviços, com pouco controle sobre gastos e voltado à classe média.

O contraste com os países europeus é imenso. Na Europa, os seguros sociais foram desenvolvidos para operários e o controle de gastos tinha o intuito de manter acessíveis os níveis dos prêmios. Em diversos países, os pagamentos a hospitais e médicos foram negociados pelos governos e/ou seguros sociais com as associações de prestadores. A distribuição de hospitais foi planejada, e a introdução de equipamentos de grande porte programada, evitando-se duplicação. Em muitos países, controles dos preços de medicamentos e esquemas estritos de referência para especialistas pelos clínicos gerais foram desenvolvidos, efetuando-se o pagamento a médicos segundo um modelo de capitaçāo (Abel-Smith, 1996). ${ }^{235}$

Resumindo, pode-se afirmar que o desenvolvimento institucional contribui para esclarecer por que razão os países com nível de vida e renda per capita semelhantes apresentam participação de gastos totais em saúde no PNB tão diferenciada. $\mathrm{O}$ desenvolvimento institucional explicita as diferenças nos gastos totais, mas não a proporção de gastos públicos. Entretanto, os determinantes da garantia de maior ou menor proteção social devem ser buscados em processos histórico-sociais mais amplos. Em particular, no nível de organização e na capacidade de mobilização, formulação de estratégias e construção de alianças da classe trabalhadora (Esping-Andersen, 1985). A análise das relações entre prestadores e consumidores trata apenas, em primeiro nível de aproximação, da alocação de recursos da economia nacional no setor saúde e não da alocação dos recursos públicos entre diversos setores.

Esse conjunto de consideraçōes a respeito dos diversos fatores que influenciam a evolução dos gastos em saúde sugere, em primeiro lugar, a partir de evidências razoáveis, que o envelhecimento populacional não leva de modo inexorável ao

225 Há evidências de que países cujos sistemas de saúde se organizam com base nesses mecanismos gastam comparativamente menos com saúde, como é o caso tradicional da Grã-Bretanha. 
aumento dos gastos em saúde. Da mesma forma que não é necessário que se tornem 'impagáveis' a assistência à saúde e o progresso médico (no bom sentido das expressões 'alívio do sofrimento' e 'prolongamento da vida com boa qualidade'). Sugere também que maior eficiência na prestação de serviços de saúde pode ser alcançada por meio do controle sobre prestadores de serviços e produtores da área da saúde indústrias de medicamentos, de equipamentos, materiais e insumos médico-hospitalares -, assim como sobre os provedores de seguro (as seguradoras). Todos esses grupos exercem forte influência no consumo de ações médico-sanitárias.

Adequadas avaliações para a admissão de novas tecnologias e produtos em saúde, normatização de condutas, mudanças nas formas de remuneração e contratação dos prestadores podem contribuir decisivamente para uma prestação de ações em saúde mais econômica sem perda da qualidade. Políticas que tiverem por finalidade o alcance de maior eficiência deveriam incluir estas modalidades de medidas de racionalização da oferta. Como será visto a seguir, a meta das políticas de contenção, porém, é mais a redução dos gastos em saúde do que o alcance de maior eficiência ou a melhoria da qualidade da atenção prestada. $\mathrm{O}$ objetivo de estabilização das taxas de contribuição para desonerar o fator trabalho leva mais facilmente a cortes e deslocamento de gastos para os segurados do que à diminuição dos custos, uma vez que este é propósito subordinado. 